\title{
Mechanisms for Torrential Rain Associated with the Mei-Yu Development during SCSMEX 1998
}

\author{
JIAN-HUA QIAN \\ Mesoscale Atmospheric Processes Branch, Laboratory for Atmospheres, NASA Goddard Space Flight Center, and Universities Space \\ Research Association, Greenbelt, Maryland \\ WEI-KUO TAO \\ Mesoscale Atmospheric Processes Branch, Laboratory for Atmospheres, NASA Goddard Space Flight Center, Greenbelt, Maryland \\ K.-M. LAU \\ Laboratory for Atmospheres, NASA Goddard Space Flight Center, Greenbelt, Maryland
}

(Manuscript received 26 March 2002, in final form 29 May 2003)

\begin{abstract}
A case of torrential precipitation associated with the mei-yu front, an Asian summer monsoon system east of the Tibetan Plateau, is studied using the coupled fifth-generation Pennsylvania State University-NCAR Mesoscale Model (MM5) and the NASA Goddard Space Flight Center Parameterization for Land-Atmosphere-Cloud Exchange model. The impact of both remote and local sources of water vapor on the location and intensity of mei-yu precipitation are studied by numerical experiments. The results demonstrate that the main source of water vapor for this heavy precipitation event over the Yangtze River Valley is the Bay of Bengal. Moisture is transported by a southwesterly low-level jet (LLJ) southeast of the Tibetan Plateau. Although the LLJ is largely manipulated by large-scale forcing, the mesoscale circulation that results from mei-yu condensational heating acts to increase the maximum wind speed of the jet. The condensation-induced local circulation strengthens the moisture transport in the LLJ, providing a positive feedback that sustains the mei-yu precipitation system. Precipitation recycling increases the total precipitation in the Yangtze River Valley only slightly, but it tends to shift the maximum rainfall center toward the warmer side of the mei-yu rain belt. This shift is due to the pronounced increase in atmospheric moisture and decrease in surface temperature over the warm side of the rain belt.
\end{abstract}

\section{Introduction}

The South China Sea Monsoon Experiment (SCSMEX) was carried out in the summer of 1998 to study the onset and evolution of the South China Sea (SCS) monsoon and its impact on rainfall variability over Southeast Asia, southern China, and adjacent regions (Lau et al. 2000). It was observed that during the break phase of the SCS monsoon in the first two weeks of June 1998, torrential rain occurred over the Yangtze River, associated with the development of a mei-yu front in central China (Ding and Li 1999). The heavy rain events, which persisted throughout the summer of 1998 and caused extensive flooding over central and northeastern China, exacted a heavy toll on the livelihood of large segments of the east Asian population, inflicting

Corresponding author address: Dr. Jian-Hua (Joshua) Qian, International Research Institute for Climate Prediction, The Earth Institute, Columbia University, Lamont Campus, P.O. Box 1000, 61 Route 9W, Palisades, NY 10964.

E-mail: jqian@iri.columbia.edu a total economic loss of over 12 billion U.S. dollars (National Climatic Center Report 1998).

The occurrence of torrential rain over the Yangtze River Valley (YRV) in the summer of 1998, as a major climate event, has been reported in a number of recent large-scale observational and general circulation modeling studies (Lau and Weng 2001; Lau and Wu 2001; Shen et al. 2001; Wang et al. 2000). In this paper, a coupled mesoscale atmosphere-land model is used to investigate the mechanisms for torrential rain, the sources and sinks of moisture, and the possible interaction between precipitation and land surface processes during the heavy rain period 11-17 June 1998. Since the development of the mei-yu front was key to the heavy precipitation over the YRV during the summer of 1998, a brief review of mei-yu moisture processes and an overview of the June 1998 mei-yu event are provided in section 2. Section 3 describes the numerical model and experimental setups. In section 4 , the water vapor sources for the mei-yu precipitation are clarified. Local precipitation recycling is studied in section 5. Section 6 is the summary and discussion. 


\section{A mei-yu primer}

\section{a. Mei-yu moisture processes}

The mei-yu front is a quasi-stationary summer monsoon precipitation system over eastern Asia (Tao and Chen 1987). The unique large-scale circulation pattern associated with the special topography of the Tibetan Plateau causes the mei-yu rainy period to last from about two weeks to over a month along the YRV. The interaction of several large-scale systems-namely, moist southwesterly monsoonal flow and the associated LLJ, dry northwesterly flow from the northern side of the Tibetan Plateau, and the subtropical high over the west Pacific Ocean-forms an environment that favors a meiyu system along the YRV all the way east toward Japan. Three key issues relevant to this study-namely, the moisture source, the LLJ, and precipitation recyclingare briefly discussed below.

The first important issue is the tracking of moisture sources. The large-scale circulation indicates that during northern summer, most of the moisture in southeastern China originates from the west and south (Ding 1994; Simmonds et al. 1999). But it is not obvious whether the moisture flux from the Bay of Bengal (BOB) or that from the SCS is more important for mei-yu precipitation. For example, in their studies of a mei-yu flood in the Sichuan Basin (near the eastern side of the Tibetan Plateau) on 11-15 July 1981, Zhou and Hu (1984) and the Chengdu Central Observatory (1982) suggested that the major moisture source for the flood was the SCS. But for the same case, Kuo et al. (1986), based on moisture flux calculations, found that the moisture transport from the BOB was considerably larger than that from the SCS.

Delineating moisture sources for mei-yu precipitation is a subtle and delicate problem, largely depending on the placement of the boundaries or interfaces through which the moisture fluxes are calculated. In earlier studies, these boundaries were often located close to the target precipitation region but far away from the moisture source regions. Chen et al. (1983a,b) calculated the moisture transport for the summer months of 1979 to 1981 and found that the moisture in the YRV was transported from the western and southern boundaries of the basin, which were linked to moisture sources from the BOB and SCS, respectively. Their results showed that moisture flux from the western boundary was larger than the southern boundary in May and vice versa in June. However, not only was the length of the southern boundary double the size of the western boundary, but their positions, at $26^{\circ} \mathrm{N}$ and $105^{\circ} \mathrm{E}$, were very close to the YRV but far away from the moisture source regions. Therefore, it is difficult to know whether the moisture flux at the southern boundary was originally from the SCS alone or from a combination of the SCS and the BOB. Shen (1983) studied atmospheric moisture transport and precipitation in the YRV in July and found that the moisture transport by the southwesterly mon- soonal flow is stronger in wet years. However, he claimed that the moisture in the southwesterly monsoonal flow is mostly from the SCS and is enhanced by land surface evaporation in southern China. Simmonds et al. (1999) compared the atmospheric water vapor fluxes and summertime precipitation of southeastern China in the domain $25^{\circ}-35^{\circ} \mathrm{N}, 110^{\circ}-120^{\circ} \mathrm{E}$ for wet and dry years. The average inward moisture flux is larger on the southern boundary than on the western boundary. However, the wet-year flux is more than double that of the dry-year flux for the western boundary (the difference is $177.9 \mathrm{~mm} \mathrm{month}^{-1}$ ), while on the southern boundary the difference is only $92.3 \mathrm{~mm} \mathrm{month}^{-1}$. Hence, it is obvious that the precipitation in southeastern China is more sensitive to changes in moisture flux through the western boundary. Notwithstanding their argument that most of the moisture inflow may actually originate from the SCS, their results indicate the importance of different moisture sources for precipitation in mei-yu systems. In fact, most of the moisture passes out of southeastern China to the east and north without delivering any precipitation. Therefore, moisture sources that actually bring forth precipitation cannot be diagnosed by merely calculating water vapor fluxes across certain interfaces.

The second important issue is the relationship between the mei-yu front and the LLJ. Mei-yu rainfall is statistically closely related to the LLJ southeast of the Tibetan Plateau (Chen and Yu 1988), and the correlation coefficient between the occurrence of severe storms and the LLJ is as high as 0.8 (Tao and Ding 1981). During mei-yu season, the lower and middle troposphere over southeastern China is dominated by southwesterly monsoonal flow, in which the strong wind with a speed exceeding $15 \mathrm{~m} \mathrm{~s}^{-1}$ is referred to as the southwesterly LLJ. It brings plenty of warm moist air from the subtropical oceans to southeastern China and fuels the precipitation in the mei-yu front. The generation and development of the LLJ and the propagation of its wind speed maximum are, to a large extent, controlled by the orographic effects of the plateau on the airflow along the western periphery of the subtropical high and the amplification of low-level meso- $\alpha$-scale cyclones (called southwest cyclones) that frequently form over southwestern China at the foot of the Tibetan Plateau (Wu and Chen 1985; Wu and Liu 1997; Orlanski 1975). When the subtropical high stretches westward and, at the same time, a plateau-related mesoscale cyclone is developing, a very strong LLJ reaching wind speeds of $20-25 \mathrm{~m} \mathrm{~s}^{-1}$ is often observed. Latent heat released by precipitation can also feed back into the LLJ through local secondary circulations (Chen et al. 1998; Chen et al. 1994).

Another unknown factor in mei-yu precipitation is the role of precipitation recycling, defined as the contribution of local evaporation to local precipitation (Brubaker et al. 1993; Eltahir and Bras 1996). Precipitationinduced surface evaporation and evapotranspiration in- 
crease atmospheric moisture, but the net effect of locally evaporated moisture on local precipitation is very much dependent on the precipitation efficiency, the fraction of moisture flowing through a region that is precipitated out, which is usually small in southeastern China (Trenberth 1999). On the other hand, local evaporation decreases the surface temperature, thus changing the thermodynamic structure of the atmosphere and in turn the precipitation (Paegle et al. 1996; Beljaars et al. 1996).

\section{b. Overview of the June 1998 mei-yu event}

During the summer of 1998, the averaged seasonal rainfall (June-August) in the YRV was over $500 \mathrm{~mm}$. Precipitation in some areas, such as the Poyang Lake and the Gan River in the Jiangxi province in the middle of the YRV, exceeded $1000 \mathrm{~mm}$, with precipitation anomalies as large as $100 \%$. The mei-yu period began in the YRV on 12 June, and 12-28 June was one of the heavy rainy periods. Over Eurasia, two blocking high patterns were observed at $500 \mathrm{hPa}$, one over the Ural Mountains, the other over the Sea of Okhotsk, which is the typical circulation at high latitudes during mei-yu season (Tao and Chen 1987). In the northwesterly flow on the southwest flank of the Okhotsk block, cold air frequently penetrated the YRV. In the subtropics, a high pressure ridge in the southeast-northwest direction was found on the 500-hPa height field over the Tibetan Plateau (Zhang et al. 2001). Warm, moist air from the southwest-southeast side of the subtropical high collided with the cold air from the northwest, triggering heavy precipitation along the mei-yu front.

Figure 1 shows the daily rain rate (millimeters day ${ }^{-1}$; here the "day" is defined as 0000-2400 UTC) observed by the Tropical Rainfall Measuring Mission (TRMM) Microwave Imager (TMI), and the 850-hPa wind vectors from the SCSMEX wind analysis (Lau et al. 2002), from 11 to 16 June 1998 . The TMI rainfall data are on $0.5^{\circ}$ grids and the winds on $2.0^{\circ}$ grids. The observational data are subject to some errors (Kummerow et al. 2001). The TMI passes over a given region only about once per day. Note that the high values on the TMI near the northwest corner of the domain do not really reflect high values of precipitation but are caused by the high-altitude topography of the Tibetan Plateau in the TMI data processing. The white diamond areas between the swathes are where the TMI precipitation information is not available. The $850-\mathrm{hPa}$ pressure level is in fact below the ground surface on the Tibetan Plateau. The SCSMEX winds at the $850-\mathrm{hPa}$ level are routinely interpolated based on objective interpolation, so that the winds over the Tibetan Plateau should be ignored (Lau et al. 2002). To validate the TMI, Fig. 2 displays the daily precipitation over land derived from gridded stational observational data (only daily data are available). Note that the "day" in this stational data is defined by local standard time (LST), that is, Beijing time from 0000 to $2400 \mathrm{LST}$, which is $8 \mathrm{~h}$ earlier than the cor- responding UTC. Despite the difference in the definition of "day," consistencies can still be found between Figs. 1 and 2. (Since the model simulations are also in UTC, the TMI data will be used for comparisons in the rest of the paper.) It is shown in Fig. 1 that mei-yu precipitation started on 12 June in the YRV, along about $28^{\circ} \mathrm{N}$ and $110^{\circ}-120^{\circ} \mathrm{E}$. It became very strong, and the belt of maximum cyclonic wind shear (along the northern edge of the LLJ) moved to a line from $\left(32^{\circ} \mathrm{N}, 130^{\circ} \mathrm{E}\right)$ to $\left(28^{\circ} \mathrm{N}\right.$, $\left.110^{\circ} \mathrm{E}\right)$ on 13 June. The torrential rain occurred south of this shear line from 12 June. Precipitation in the YRV was relatively small on 14 and 15 June but increased on 16 June. Corresponding to the heavy precipitation events, a meso- $\alpha$-scale cyclone in the lower troposphere passed through the YRV from west to east from late 11 June to 13 June (see Fig. 5). Subsequently, another one passed through from 14 to 17 June. The heavy precipitation over the ocean around $28^{\circ}-32^{\circ} \mathrm{N}, 120^{\circ}-130^{\circ} \mathrm{E}$ is also associated with these mesoscale cyclones (e.g., the heavy oceanic rainfall is south of the cyclonic wind circulation over the Yellow Sea on 13 June). The cyclonic wind shear line is located along the low pressure trough of the mesoscale cyclones. Figure 1 also shows that a strong southwesterly monsoonal flow at $850 \mathrm{hPa}$ persisted throughout the entire simulation period from 11 to 16 June over southeastern China, with wind speeds exceeding $15 \mathrm{~m} \mathrm{~s}^{-1}$ over a vast area south of the Yangtze River. Strong southwesterly flow is observed over the BOB (west of the model domain, thus not shown), which is connected to the Indian monsoon system. However, low-level southwesterly wind speeds over southwestern China and the Indochina peninsula are small due to the obstruction of the southeastern edge of the YunnanGuizhou Plateau. The 200-hPa circulation (not shown) is dominated by the south Asian high pressure system centered over the Tibetan Plateau. The south Asian high moves slightly eastward and the northwesterly wind along its northeast flank strengthens from 11 to 13 June.

\section{Model setup}

The mathematical tool for this study is a coupled mesoscale atmosphere-land model (Lynn et al. 2001). The atmospheric component is the nonhydrostatic fifthgeneration Pennsylvania State University-National Center for Atmospheric Research (PSU-NCAR) Mesoscale Model (MM5) version 2.7 containing various boundary layer, convection, and radiation parameterization schemes (Dudhia 1993; Grell et al. 1994). The land component is the National Aeronautics and Space Administration (NASA) Goddard Space Flight Center (GSFC) Parameterization for Land-Atmosphere-Cloud Exchange (PLACE) model (Wetzel and Boone 1995). PLACE has been a very active participant in two major international intercomparison projects, sponsored by the World Climate Research Programme/Global Energy and Water Cycle Experiment (WCRP/GEWEX): the Project for the Intercomparison of Land Surface Parameteri- 

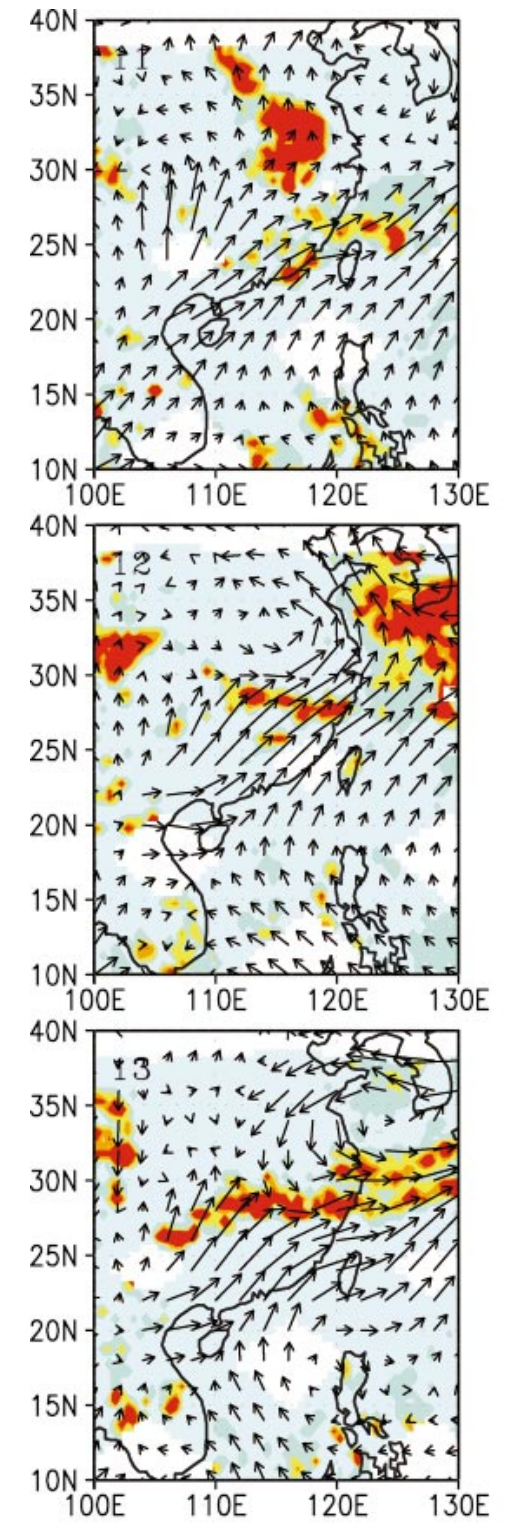
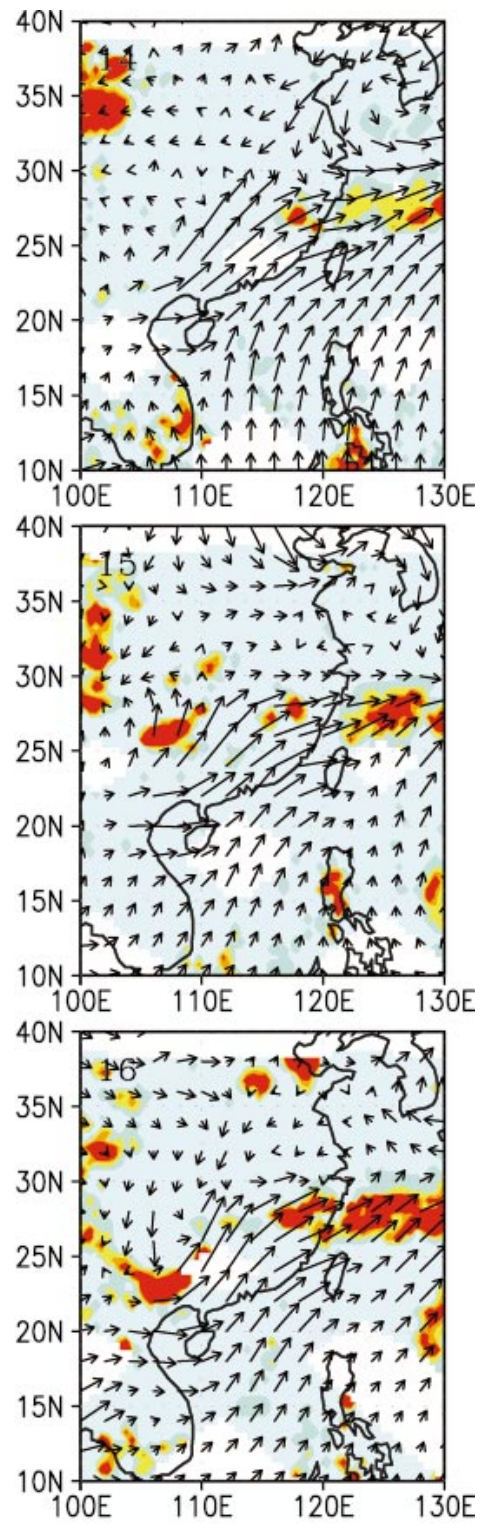

$\mathrm{ms}^{-1}$

$1 \quad 10 \quad 30 \quad 50$

FIG. 1. Observed TMI rain rate (mm day ${ }^{-1}$; from 0000 to 2400 UTC; data only available in the shaded area) and observed SCSMEX 850-hPa wind ( $\left.\mathrm{m} \mathrm{s}^{-1}\right)$, 11-16 Jun 1998.

zation Schemes (PILPS; Henderson-Sellers et al. 1993, 1995) and the Global Soil Wetness Project (GSWP; Boone and Wetzel 1999). These works have demonstrated that PLACE is as accurate as other widely used GCM parameterizations such as the Biosphere-Atmosphere Transfer Scheme (BATS). However, PLACE has been specifically designed to be applied to mesoscale models with grid resolutions of $100 \mathrm{~km}$ or smaller. Considered in PLACE are the subgrid surface heterogeneity and the feedbacks between soil, the land surface, vegetation, and entraining shallow cumulus clouds. Therefore, soil moisture interacts with precipitation, evaporation, infiltration, runoff, and soil water drainage to bedrock. There are 8 soil surface types and 14 vegetation types in PLACE. For this experiment, the initial soil temperature and soil moisture profiles are prescribed as functions of surface types and are forced by the specific humidity and virtual potential temperature supplied at 

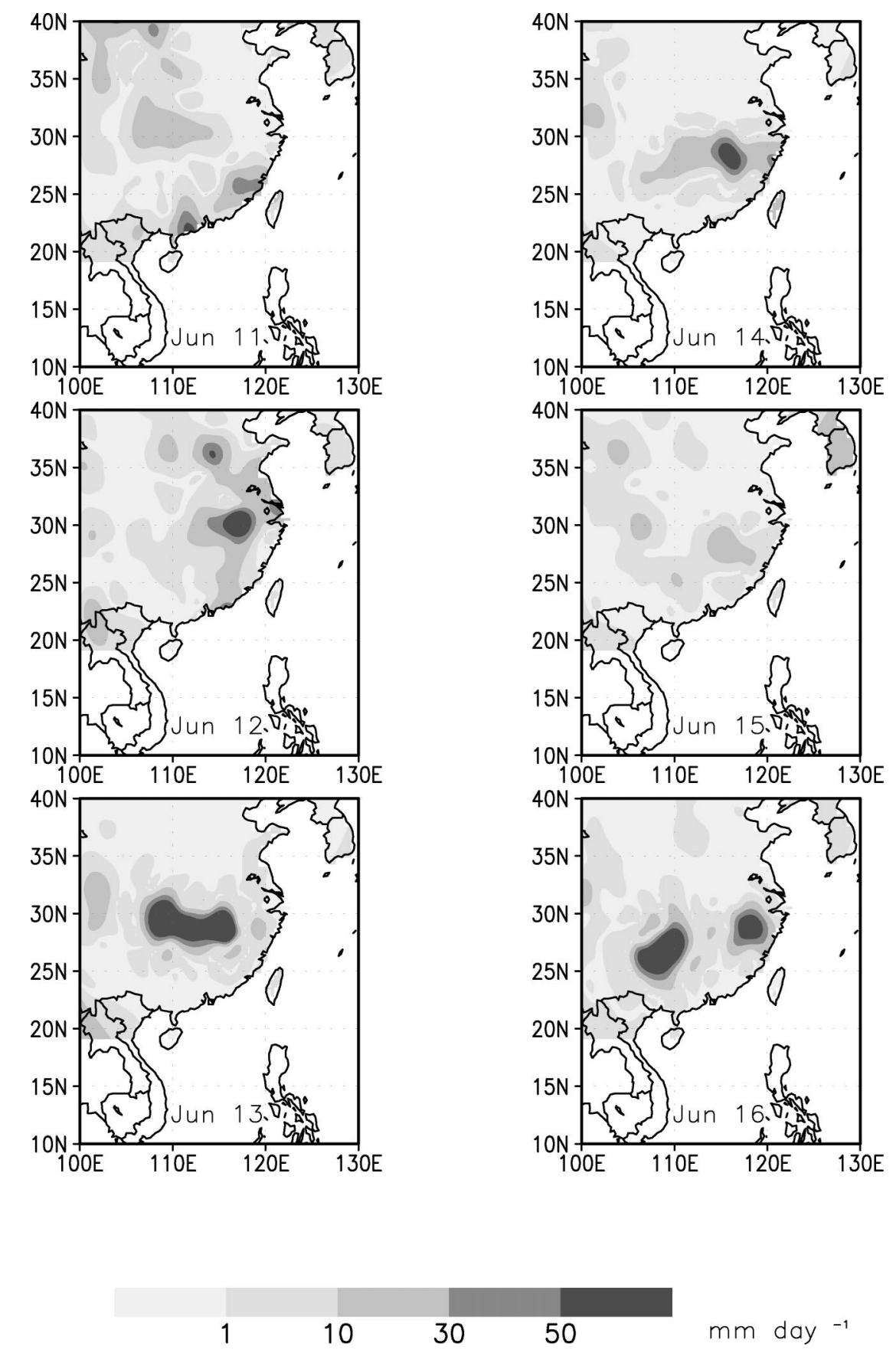

FIG. 2. Station observations of daily rain rate ( $\mathrm{mm} \mathrm{day}^{-1}$; from 0000 to $2400 \mathrm{LST}$ ).

the resolution of the atmospheric model MM5. Because of the restriction of data availability, the validation of PLACE with in situ observations and the off-line initialization of soil variables have not been carried out in this case over the YRV. However, it is considered sufficient for the current study because only the interface of precipitation-evaporation interaction is essential in the sensitivity experiment of local moisture recycling. At the lateral boundary, MM5 is driven by the European
Centre for Medium-Range Weather Forecasts (ECMWF) Tropical Ocean Global Atmosphere (TOGA) analysis of height, temperature, wind, and relative humidity every $12 \mathrm{~h}$ at global $2.5^{\circ}$ grids on the earth's surface and 13 atmospheric pressure levels (1000, 925, 850, 700, 500, 400, 300, 250, 200, 150, 100, 70, and $50 \mathrm{hPa}$ ). Over the ocean, the National Centers for Environmental Prediction (NCEP) sea surface temperature (SST) is used as lower boundary conditions. 


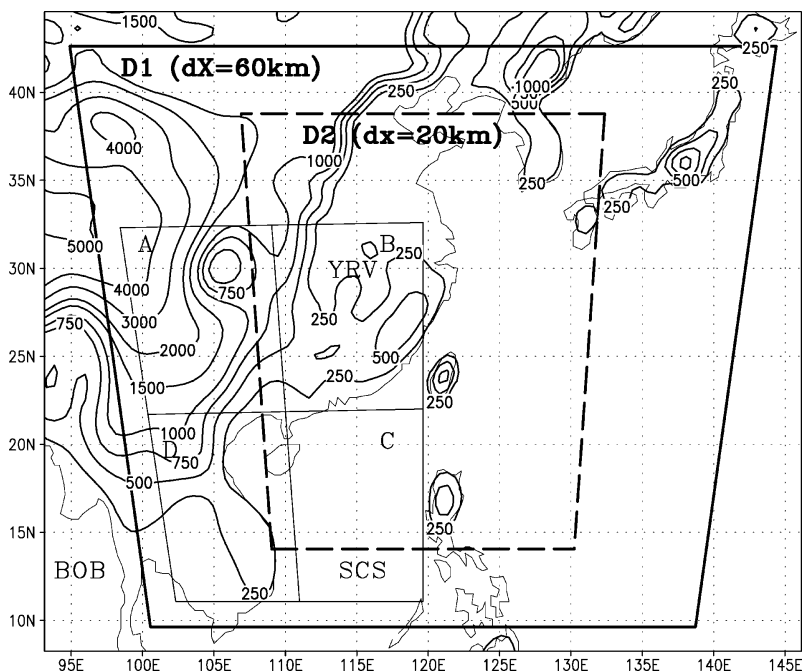

FIG. 3. Model outer domain D1 (thick solid box with grid size of $60 \mathrm{~km}$ ), inner domain D2 (thick dashed box with grid size of $20 \mathrm{~km}$ ), and the hydrology budget calculation domains A, B, C, and D. Topography is shown by the contours (m).

Instead of setting the interfaces for flux calculations close to the YRV, the outer model-domain boundaries will be set close to the moisture source regions of the BOB and SCS. By directly reducing the moisture supply from each source region, the impact on mei-yu precipitation will be determined.

The double-nested model domains cover southeastern Asia, as shown in Fig. 3. Topography is shown by contours, and the locations of the BOB, SCS, and YRV are also denoted. On a Lambert conformal map, the outer domain D1 (thick solid box) has $73 \times 64$ grid points with $\Delta X=60 \mathrm{~km}$, centered at $27.5^{\circ} \mathrm{N}, 120^{\circ} \mathrm{E}$. The southwestern corner of the outer domain is near $10^{\circ} \mathrm{N}, 100^{\circ} \mathrm{E}$, which is close to the southwestern corner of the Indochina peninsula, so that the western boundary faces the BOB and the southern boundary is midway over the SCS. In terms of general circulation, the southwestern corner of the outer domain lies roughly in between the southwesterly LLJ and flow south of the LLJ. The outer domain is set in such a way that the effects from the BOB and SCS can be separated. Two-way nested within
D1, the inner domain D2 (thick dashed box) has $136 \times$ 109 grid points with $\Delta x=20 \mathrm{~km}$ and includes the northern SCS, eastern China, and the adjacent ocean. The mei-yu front lies across the middle of the inner domain in the east-west direction. For the simulation of vertical motion associated with the heavy precipitation in the high-resolution inner domain, the inclusion of nonhydrostatic dynamics in the atmospheric model is important (Qian and Kasahara 2003; Kasahara and Qian 2000). Vertically, MM5 uses a terrain-following $\sigma$ coordinate based on reference pressure, $\sigma=\left(p_{0}-\right.$ $\left.p_{t}\right) /\left(p_{s}^{*}-p_{t}\right)$, where $p_{0}$ is the reference state pressure in the atmosphere, $p_{s}^{*}$ is the reference surface pressure that is constant with time and depends on the altitude of orography, and $p_{t}$ is the atmospheric pressure at the model top, which is $100 \mathrm{hPa}$ in this experiment. In total, 24 levels (i.e., 23 layers) are used for MM5 ( $\sigma=1.0$, $0.99,0.98,0.96,0.93,0.89,0.85,0.8,0.75,0.7,0.65$, $0.6,0.55,0.5,0.45,0.4,0.35,0.3,0.25,0.2,0.15,0.1$, $0.05,0.0)$, with $\sigma=1.0$ corresponding to the bottom of the atmosphere. Coupled at the bottom of MM5, the land surface model PLACE has five layers for soil moisture plus two surface water storage reservoirs, and seven layers of soil temperature (Wetzel and Boone 1995; Lynn et al. 2001). The Kain-Fritsch convection scheme, Blackadar PBL scheme, Dudhia simple ice scheme, and Goddard radiation scheme are chosen for the parameterization of atmospheric processes. The coupled model was run for a week from 0000 UTC 11 June to 0000 UTC 18 June 1998, with a time step of 3 min for D1 and $1 \mathrm{~min}$ for $\mathrm{D} 2$.

The coupled model, called MM5P, is used to investigate various aspects of the remote moisture sources, the interaction between precipitation and the LLJ, and the local effect of precipitation-evaporation feedback (precipitation recycling) in a mei-yu event on 11-17 June 1998. The numerical experiments are described in Table 1. The experiment NF (no feedback between precipitation and evaporation) is used to examine the sensitivity of local moisture recycling. Experiments E80, S80, W80, and W50 (reducing horizontal moisture flux at all vertical levels at the eastern, southern, and western boundary, respectively) are

TABLE 1. MM5P numerical experiments.

\begin{tabular}{ll}
\hline \hline \multicolumn{1}{c}{ Experiment } & \multicolumn{1}{c}{ Description } \\
\hline CTRL (control run) & Unreduced lateral moisture flux and with precipitation recycling \\
E80 & Moisture at east boundary is 80\% of that of CTRL \\
S80 & Moisture at south boundary is 80\% of that of CTRL \\
W80 & Moisture at west boundary is 80\% of that of CTRL \\
W50 & Moisture at west boundary is 50\% of that of CTRL (at all levels) \\
W50 $(1.0-0.7)$ & Same as W50, but moisture is reduced only between $\sigma=1.0$ and 0.7 \\
W50 $(0.7-0.4)$ & Same as W50, but moisture is reduced only between $\sigma=0.7$ and 0.4 \\
W50 $(0.4-0.0)$ & Same as W50, but moisture is reduced only between $\sigma=0.4$ and 0.0 \\
W50 $(1.0-0.85)$ & Same as W50, but moisture is reduced only between $\sigma=1.0$ and 0.85 \\
W50 $(0.85-0.7)$ & Same as W50, but moisture is reduced only between $\sigma=0.85$ and 0.7 \\
NF (no feedback) & Same as CTRL, but without precipitation recycling \\
\hline
\end{tabular}


used to determine the location of remote moisture sources that contributed to the mei-yu torrential rain. After discerning that the intensity of mei-yu precipitation is more sensitive to moisture from the western boundary, the five experiments W50(1.0-0.7), W50(0.7-0.4), W50(0.4-0.0), W50(1.0-0.85), and W50 $(0.85-0.7)$ are used to determine the importance of moisture in different $\sigma$ layers at the western boundary.

\section{Large-scale impact of remote moisture sources}

\section{a. Comparison of control simulation with observations}

First, the control simulation, denoted by CTRL, is compared with observations for validation. In the CTRL, the moisture flux at all lateral boundaries of the model outer domain is unreduced (at all levels from $\sigma$ $=1$ to 0 ), and the interaction between precipitation and evaporation is also retained. The simulated daily rain rate and $850-\mathrm{hPa}$ winds from 11 to $16 \mathrm{June}$ are displayed in Fig. 4. It shows that a mature mei-yu rain belt (Chen and Chang 1980) forms on 13 June in the YRV. The 6hourly rain rates (not shown) indicate that mei-yu precipitation starts at 1800 UTC 12 June, along a latitude of about $28^{\circ} \mathrm{N}$ with a slight west-southwest-east-northeast orientation. A number of precipitation centers, separated by $200-300 \mathrm{~km}$, propagate eastward along the rain belt. Very heavy rainfall is produced in the central part of the YRV where the flood took place. Similar to the TMI observations, the simulated mei-yu rain belt evanesces on 14 June, partly returns on 15 June, and fully recovers on 16 June.

There is also some sporadic simulated precipitation near the southern boundary of the model domain. In the TMI observations (Fig. 1), even though some areas near the southern boundary are empty of data in the gaps between the satellite swathes, some small-scale heavy precipitation can still be observed. Climatologically, this area is near the intertropical convergence zone (ITCZ), which has persistent convection. Station data near the southern boundary are not available in Fig. 2. Therefore, the accuracy of precipitation near the southern boundary cannot be fully validated. Although this may cause uncertainties in estimating the water budget near the southern boundary, it should not be a major concern since our focus is in the YRV.

Compared to the observed 850 -hPa winds in Fig. 1, the simulated winds in Fig. 4 show that the model reproduced the southwesterly LLJ in the YRV and southeastern China, persisting through the entire simulation period. (Note that the 850 -hPa model level is below the ground surface of the Tibetan Plateau; therefore, simulated winds are not available there.) The cyclonic wind shear at the northern edge of the LLJ is also evident. The evolution of the $850-\mathrm{hPa}$ height field shows that a meso- $\alpha$-scale low pressure center gradually deepens while passing through the model domain eastward along the zonal belt $30^{\circ}-35^{\circ} \mathrm{N}$ from 11 to 13 June (Fig. 5), and similarly another one from 14 to 17 June. Correspondingly, the feature of the eastward moving mesoscale cyclonic wind circulation is also found in Fig. 4 as well as in Fig. 1. However, some discrepancies in wind field also exist. Over the Indochina peninsula, although the direction of the simulated wind is correct, the wind speed in Fig. 4 is slightly larger than that in the SCSMEX observations in Fig. 1. Also, the southwesterly wind in the northern part of the SCS is weaker in Fig. 4 than in Fig. 1 in the second half of the simulation period. But overall, the low-level wind field associated with the mei-yu system is simulated reasonably well.

The 200-hPa height (solid) and wind, 500-hPa height (solid) and temperature (dashed), and $850-\mathrm{hPa}$ height (solid), temperature (dashed), and wind fields (to show wind shear) are shown in Fig. 5 at two times: one is the initial condition at 0000 UTC 11 June, and the other is at 1200 UTC 13 June, when the maximum mei-yu rainfall over land is observed. The 200 -hPa fields indicate that the eastern part of the south Asian high is in the model domain. Northeast of the south Asian high are the strong northwesterly winds behind the east Asian trough. The trough moves to the east coast of China, and northwesterly winds increase from 11 to 13 June, as was observed. At $500 \mathrm{hPa}$, a subtropical high is over the western Pacific Ocean and is strengthened and advances northwestard from 11 to 13 June. In the 500$\mathrm{hPa}$ temperature field, however, no strong temperature gradient parallels the mei-yu rain belt on 13 June. Similarly, a strong temperature gradient is also absent at $850 \mathrm{hPa}$ over land near the mei-yu precipitation. However, over the ocean near $35^{\circ} \mathrm{N}, 130^{\circ} \mathrm{E}$, a strong temperature gradient is evident. This feature in the temperature field is similar to the diagnostic study by Chen and Chang (1980) for a summer monsoon trough case, in which the western section of the mei-yu trough over mainland China is quite different from the central and eastern sections of the trough over the Pacific Ocean. The western section is characterized by a weak temperature gradient and resembles barotropic, warm core tropical disturbances driven by convective heating, while the central and eastern sections are typical of a midlatitude frontal system with strong baroclinicity. The 850 -hPa wind field on 13 June is also similar to that of Chen and Chang (1980). Figure 5f shows strong cyclonic wind shear along the mei-yu trough extending from the low pressure center (meso- $\alpha$-scale cyclone) at $37^{\circ} \mathrm{N}, 128^{\circ} \mathrm{E}$ west-southwest to $29^{\circ} \mathrm{N}, 107^{\circ} \mathrm{E}$. The maximum mei-yu precipitation stretched roughly from $32^{\circ} \mathrm{N}$, $130^{\circ} \mathrm{E}$ to $28^{\circ} \mathrm{N}, 110^{\circ} \mathrm{E}$, south of the wind shear line.

To have a closer look at the intensity and location of the mei-yu rain belt in the YRV, the meridional distribution of daily rain rate (millimeters day ${ }^{-1}$ ) near the area of torrential rain, averaged zonally from $110^{\circ} \mathrm{E}$ to $122^{\circ} \mathrm{E}$ (the land portion of the mei-yu rain belt), is dis- 

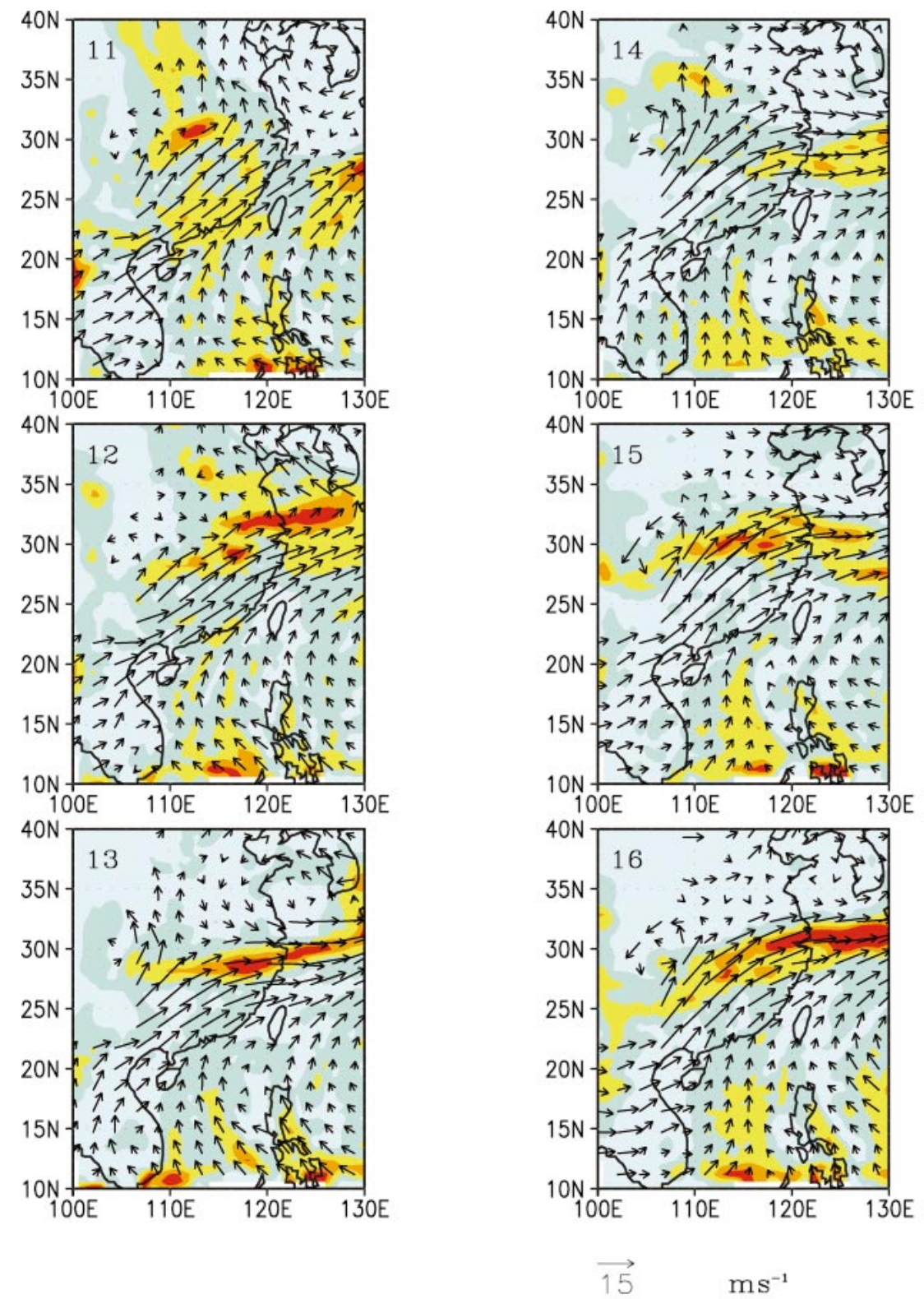

$1 \quad 10 \quad 30 \quad 50 \quad \mathrm{~mm} \mathrm{day}^{-1}$

FIG. 4. The daily rain rate $\left(\mathrm{mm} \mathrm{day}^{-1}\right.$; from 0000 to $\left.2400 \mathrm{UTC}\right)$ and $850-\mathrm{hPa}$ wind $\left(\mathrm{m} \mathrm{s}^{-1}\right)$ for the control run CTRL, 11-16 Jun 1998.

played in Fig. 6 for station observations (thick long dash), TMI observations (dot-dash-circle), and the CTRL simulation (solid). Again, the "day" for the station observations is in Beijing time, which is $8 \mathrm{~h}$ earlier than the UTC used in the TMI observational and modelsimulated data. The precipitation falls over a broad area on 11 and 12 June then narrows down around $28^{\circ} \mathrm{N}$, especially in the TMI data. The simulation agrees with observations that the precipitation narrows and reaches its maximum intensity on 13 June centered around $28^{\circ}-$ $29^{\circ} \mathrm{N}$. The peak zonally averaged TMI rainfall is as large as $100 \mathrm{~mm} \mathrm{day}^{-1}$; the model-simulated rainfall and station observations reach $60 \mathrm{~mm}$ day $^{-1}$. The TMI and simulated rainfalls decrease on 14 June when the lowlevel mesoscale cyclone over the Yellow Sea (Fig. 5f) moves out of the eastern boundary of the model domain. Because the station rainfall data is only available at daily resolution, it is impossible to transform the data from LST to UTC. A portion of the station precipitation on 14 June (LST) could have actually fallen on 13 June 


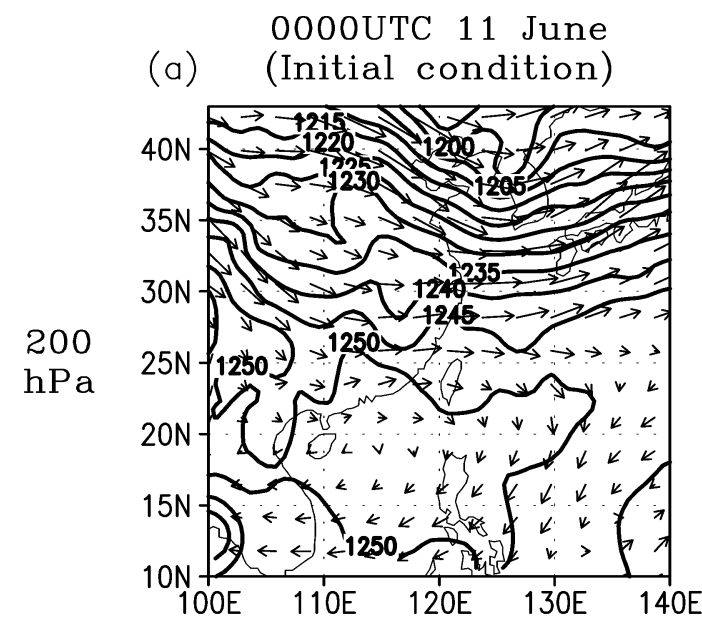

(b)

$$
\overrightarrow{40} \mathrm{~ms}^{-1}(200 \mathrm{hPa})
$$

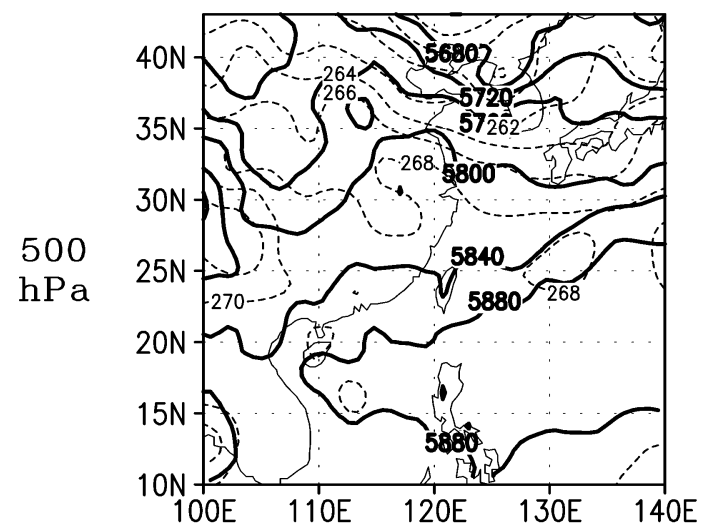

(c)

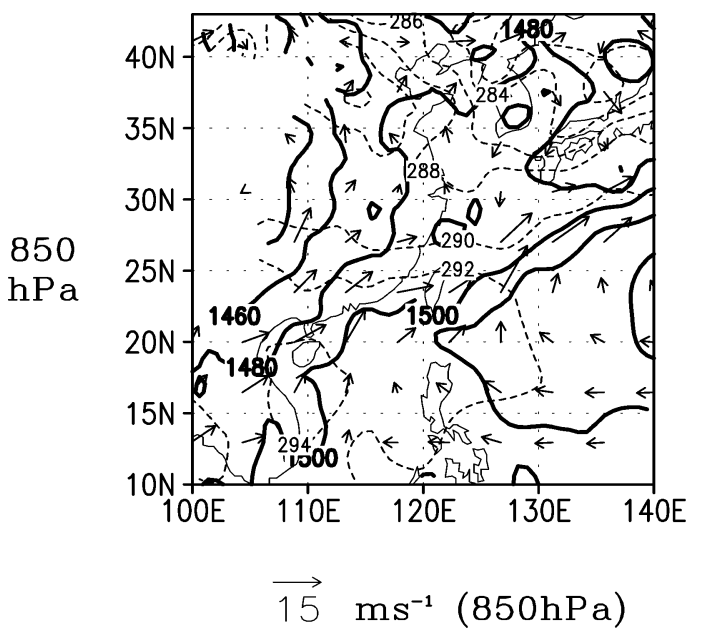

(d)

1200UTC 13 June

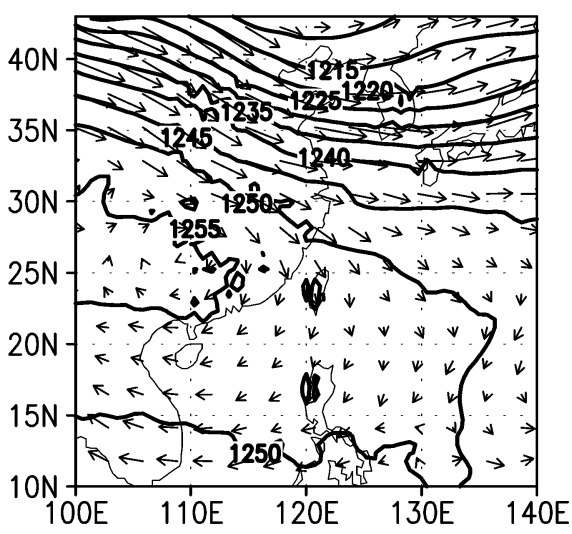

(e)

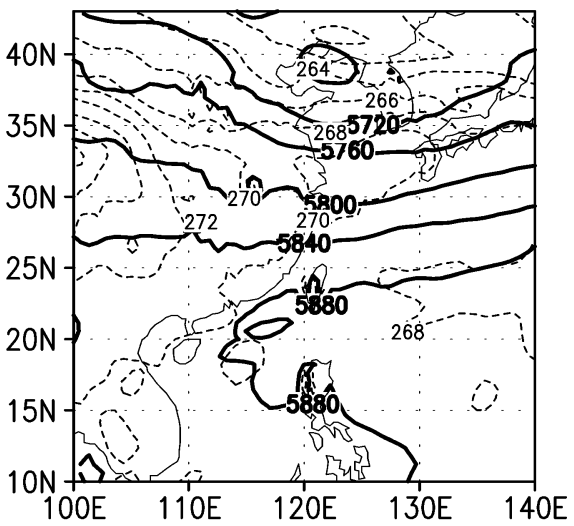

(f)

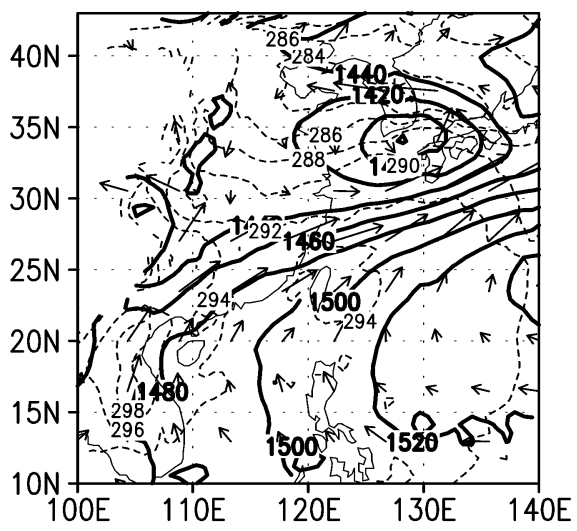

FIG. 5. (a), (d) Height (dam; solid) and wind ( $\mathrm{m} \mathrm{s}^{-1}$; vector) at $200 \mathrm{hPa}$, (b), (e) height (m; solid) and temperature (K; dashed) at $500 \mathrm{hPa}$, and (c), (f) height (m; solid), wind ( $\mathrm{m} \mathrm{s}^{-1}$; vector), and temperature (K; dashed) at $850 \mathrm{hPa}$ for the CTRL, at (left) 0000 UTC 11 Jun and (right) 1200 UTC 13 Jun. 

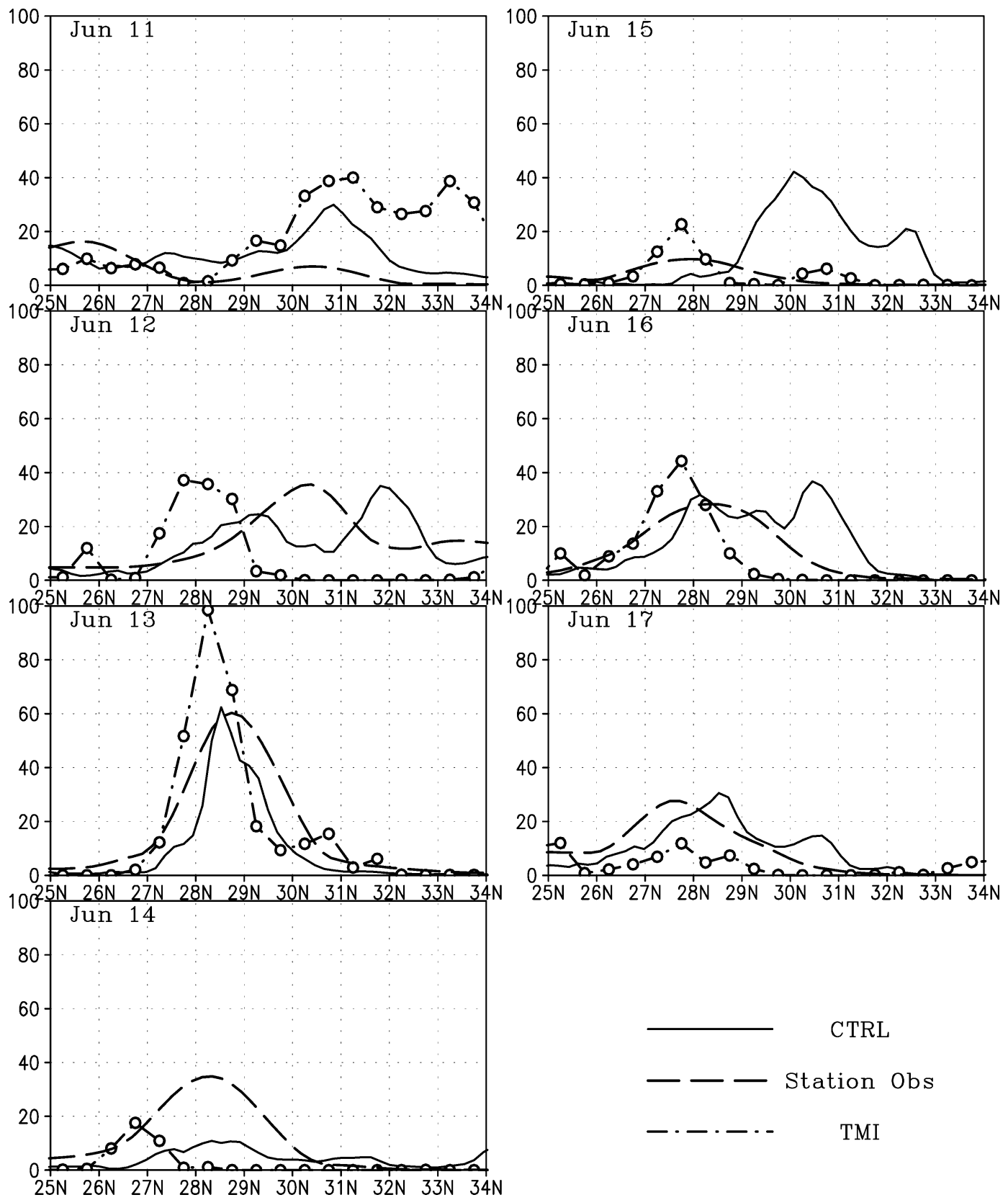

FIG. 6. Meridional distribution of daily rain rate $\left(\mathrm{mm} \mathrm{day}^{-1}\right)$, averaged from $110^{\circ}$ to $122^{\circ} \mathrm{E}$ for station observations (long dashed), TMI observations (dot-dash-circle), and the CTRL (solid).

(UTC). Rainfall increases again later on 15 and 16 June, with another $850-\mathrm{hPa}$ mesoscale cyclone passing through the domain from west to east. However, the model produces more rainfall than was observed on 15 June. On 16 June, there is another peak in TMI rainfall over $27^{\circ}-28^{\circ} \mathrm{N}$. The model also produces a large amount of rainfall but over a broader belt, roughly $27^{\circ}-31^{\circ} \mathrm{N}$. The location of the simulated precipitation is somewhat closer to the station observations but shifted slightly north of that for the TMI.

The comparison indicate that, despite some discre- pencies in the precipitation and wind fields, the control simulation CTRL generally reproduces the spatial pattern and time evolution of the mei-yu system reasonably well, so that the model is suitable for studying the mechanisms of mei-yu moisture processes.

\section{b. Remote moisture sources}

The remote moisture sources that physically provide moisture for mei-yu precipitation are examined. First, the CTRL is compared with the following four exper- 
iments: 1) W80, in which the atmospheric water vapor flux across the western lateral buffer zone of the outer domain is reduced by $20 \%$ (i.e., to $80 \%$ of the CTRL); 2) $S 80$, in which the water vapor flux is reduced by $20 \%$ across the southern buffer zone; 3) E80, in which the water vapor flux is reduced by $20 \%$ across the eastern buffer zone; and 4) W50, in which the water vapor flux is reduced by $50 \%$ across the western buffer zone. The width of the lateral buffer zone is $5 \Delta X$. In these four experiments, the lateral boundary moisture flux is reduced at all $\sigma$ levels. To study moisture transport, it is desirable to keep the atmospheric circulation as close to the CTRL as possible. Therefore, in the E80, S80, and W80 runs, the boundary moisture is reduced by only $20 \%$ so that the momentum field is not significantly altered. The W50 run is to confirm the effect of moisture from the west after finding that it is the most sensitive for mei-yu precipitation. The model setups for the above four runs are exactly the same as the CTRL except that the moisture flux along one side of the outer model domain is reduced by a prescribed percentage. Therefore, their differences from the CTRL should reflect the impact of remote moisture transport from various sources.

The numerical results show that the intensity of meiyu precipitation is not reduced in experiments $\mathrm{S} 80$ and E80 (as will be shown in Figs. 9c and 9d). However, the reduction of mei-yu precipitation is considerable in experiment W80 (comparisons to the CTRL on 13 June will be shown in Fig. 9b). If the water vapor flux from the western boundary is further reduced to $50 \%$ (W50), the reduction of mei-yu precipitation is even greater. Figure 7 shows the daily rain rate and $850-\mathrm{hPa}$ winds from 11 to 14 June for the W50 case. Compared to the CTRL in Fig. 4, W50 precipitation in the YRV gradually decreases from the first day of the simulation, and meiyu precipitation is reduced remarkably on 13 June, with the maximum rainfall reduced from 60 to about $10 \mathrm{~mm}$ day $^{-1}$ (as can also be seen in Fig. 8). Hence, it is clear that the moisture that fuels the mei-yu precipitation is mostly from the BOB and is transported by the southwesterly LLJ. These experiments also reveal that, for the mei-yu rainfall in the YRV, moisture from the equatorial region from the southern boundary of the outer domain at $10^{\circ} \mathrm{N}$ is less important. The results also imply that evaporation over the northern SCS and the land area of southern China is not a major moisture source of the precipitation in the YRV for this case, otherwise, the mei-yu rainfall would not be almost absent over the YRV in run W50. Evaporation over the SCS will be calculated in section $4 \mathrm{~d}$.

Next, the moisture contributions in different vertical layers at the western boundary need to be discerned. In addition to W50(1.0-0.0), in which moisture flux at the western boundary is reduced at all $\sigma$ levels (1.0-0.0), five more experiments are done in which the moisture flux is only reduced in a particular layer: 1) W50(1.0$0.7)$, flux is reduced only in the lower atmosphere be- tween the ground and $\sigma=0.7 ; 2)$ W50(0.7-0.4), only in the middle atmosphere between $\sigma=0.7$ and $0.4 ; 3$ ) W50(0.4-0.0), in the upper atmosphere between $\sigma=$ 0.4 and 0.0 ; 4) W50(1.0-0.85); and 5) W50(0.85-0.7). The last two experiments are used to further delineate the impact of moisture in the lower atmosphere. Figure 8 displays the meridional distribution of the zonally averaged $\left(110^{\circ}-122^{\circ} \mathrm{E}\right)$ precipitation on 13 June for the above experiments. Compared to the CTRL, which has a peak rain rate of about $60 \mathrm{~mm} \mathrm{day}^{-1}$, the precipitation in the W50(1.0-0.0) and W50(1.0-0.7) runs are greatly reduced, with the peak being only about $20 \%$ of that of the CTRL. The closeness of the W50(1.0-0.7) to the W50(1.0-0.0) indicates that the moisture contributing to the precipitation is concentrated in the lower atmosphere below $\sigma=0.7$ (which corresponds to $p=730$ $\mathrm{hPa}$, where $\left.p_{s}^{*}=1000 \mathrm{hPa}\right)$. In the W50(0.7-0.4) run, the peak rain rate is about $50 \mathrm{~mm}_{\text {day }}^{-1}$; therefore, the impact of mid atmospheric moisture is weak but still notable. Rainfall in the W50(0.4-0.0) run is quite close to the CTRL, indicating that upper-atmospheric moisture is insignificant in this torrential rain case. Rainfall in the W50(1.0-0.85) and W50(0.85-0.7) runs is of similar magnitude, which is halfway between that of the CTRL and W50(1.0-0.0). Hence, both the moisture below $\sigma=0.85$ (which corresponds to $p=865 \mathrm{hPa}$, where $p_{s}^{*}=1000 \mathrm{hPa}$ ) and that between $\sigma=0.85$ and 0.7 , at the western boundary, plays an important role in the mei-yu precipitation.

\section{c. Interaction between mei-yu precipitation and the LLJ}

As seen in Fig. 7, the 850-hPa southwesterly monsoonal flow in southeastern China in W50 is almost as strong as in the CTRL. This implies that its formation is mostly due to large-scale conditions rather than local latent heating. However, as suggested by many studies (Chen et al. 1994; Cho and Chen 1995; Hsu and Sun 1994; Nagata and Ogura 1991; Chen and Chen 1995), the LLJ is also related to the local thermodynamic forcing. The relationship between condensational heating and the LLJ are examined by analyzing the difference field between the CTRL and the other experiments. Difference fields for precipitation and $850-\mathrm{hPa}$ winds between the CTRL and W50, W80, S80, and E80 are shown in Figs. 9a, 9b, 9c, and 9d, respectively, on 13 June, when mei-yu precipitation is at a maximum.

Figures $9 \mathrm{a}$ and $9 \mathrm{~b}$ clearly show that, compared to the CTRL, mei-yu precipitation is considerably reduced in W80 and almost totally removed in W50. Therefore, the difference between the CTRL and W50 can be utilized to illustrate the effect of mei-yu condensational heating on the change in the local mesoscale circulation. In Figs. 9a (CTRL - W50) and 9b (CTRL - W80), the change in the local circulation, as displayed by the wind difference field, shows a cyclone-like pattern over the area slightly west of the mei-yu precipitation center near 
June 11

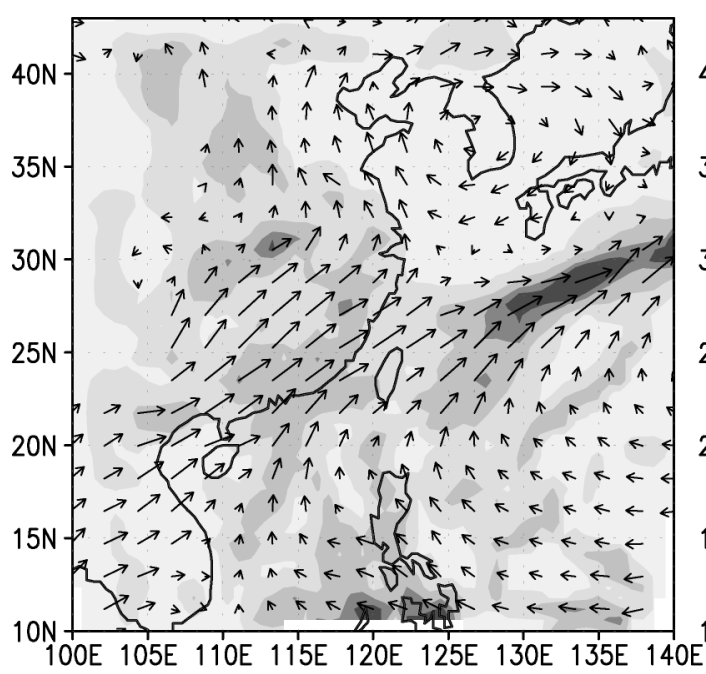

June 13

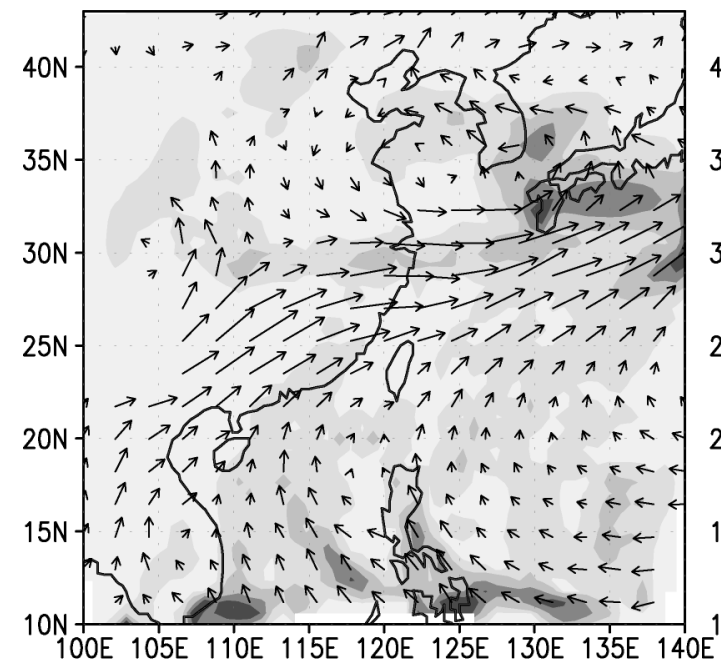

June 12

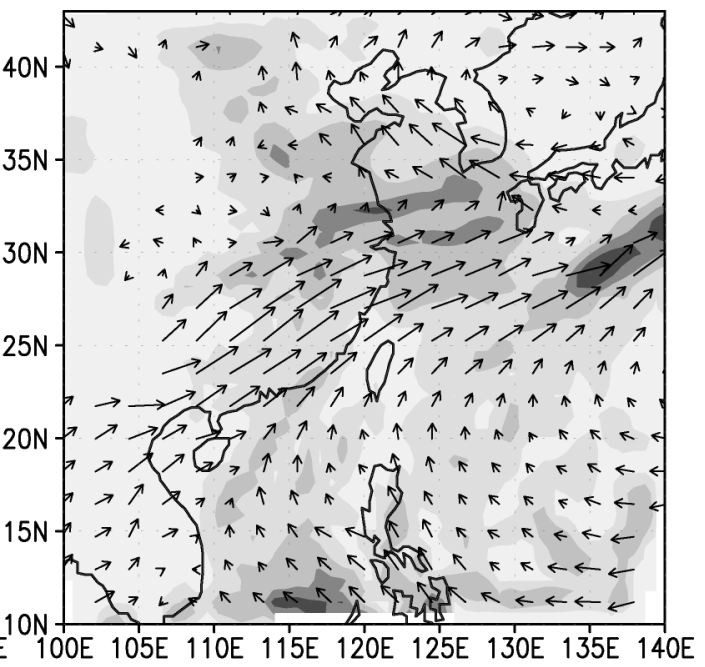

June 14

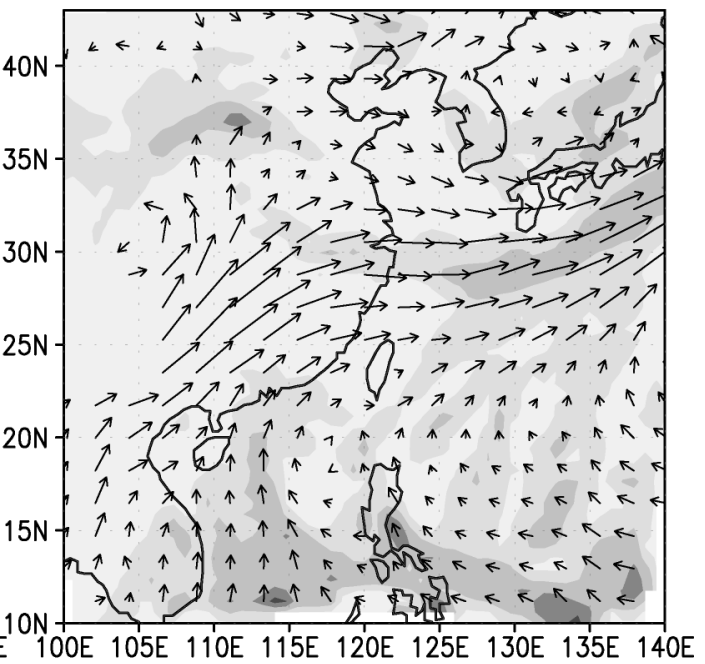

$\overrightarrow{15}$

$\mathrm{m} / \mathrm{sec}$

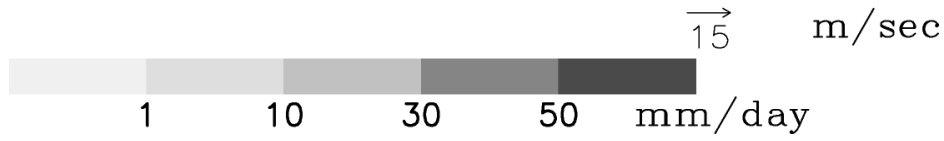

FIG. 7. Daily rain rate (mm day $\left.{ }^{-1}\right)$ and 850-hPa wind $\left(\mathrm{m} \mathrm{s}^{-1}\right)$ for W50, 11-14 Jun 1998.

$\left(28^{\circ} \mathrm{N}, 115^{\circ}-120^{\circ} \mathrm{E}\right)$. This change in circulation is caused by the latent heat released from the torrential rain, and the change in wind is proportional to the change in precipitation intensity, as evidenced by comparing Figs. $9 \mathrm{a}$ and $9 \mathrm{~b}$. A positive westerly wind difference (CTRL $-\mathrm{W} 50)$ is found in the region $\left(27^{\circ}-29^{\circ} \mathrm{N}, 110^{\circ}-125^{\circ} \mathrm{E}\right)$ where the LLJ is located. Thus, the mei-yu condensational heating acts to increase the westerly wind speed of the LLJ. At some grid points, the southwesterly wind speed can change as much as $5 \mathrm{~m} \mathrm{~s}^{-1}$, but the difference is small at most grid points far away from the mei-yu rain belt in the LLJ region. The cross-frontal component of the wind difference, which is basically ageostrophic, is larger than the along-front component. This intensifies convergence into the mei-yu rain belt. Therefore, the LLJ fuels the condensation, and in turn the condensation strengthens the LLJ as well as increases the convergence, forming a self-sustained system.

In the difference field between the CTRL and S80 (Fig. 9c), the wind change is like a weak cyclone over the SCS, which is induced by the moisture from the southern boundary. The resulting wind difference in the LLJ region is opposite to the direction of the jet wind; therefore, the moisture from the southern boundary acts 


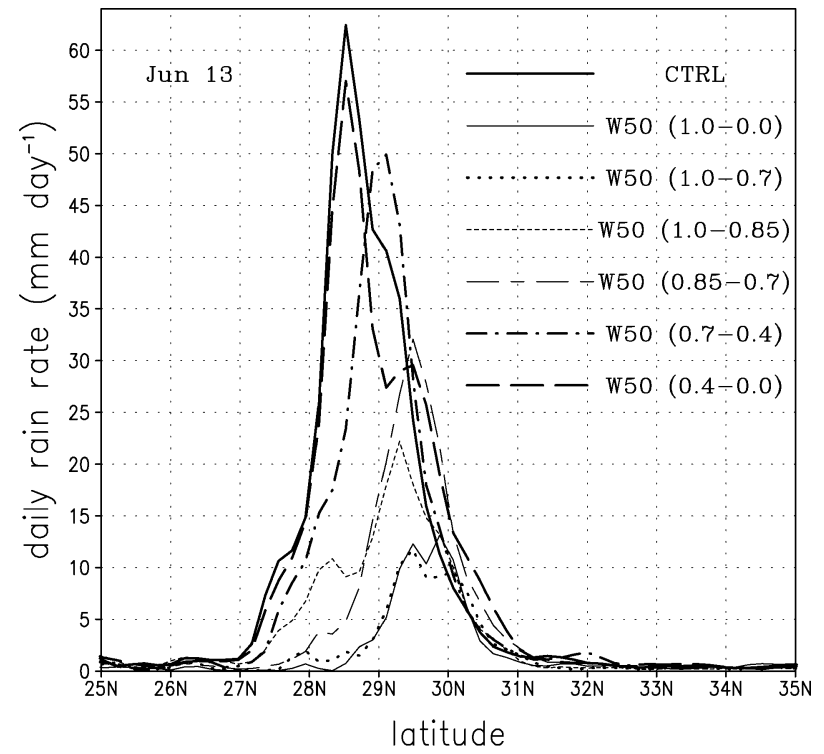

FIG. 8. Meridional distribution of daily rain rate $\left(\mathrm{mm} \mathrm{day}^{-1}\right)$, averaged from $110^{\circ}$ to $122^{\circ} \mathrm{E}$ on 13 Jun for the CTRL (thick solid), W50 (thin solid), W50(1.0-0.7) (dot), W50(0.7-0.4) (thick dash-dot), W50(0.4-0.0) (thick long dash), W50(1.0-0.85) (short dash), and W50(0.85-0.7) (long-short dash).

to slightly weaken the LLJ. The wind and precipitation differences between the CTRL and E80 are very small (Fig. 9d), indicating a negligible moisture effect from the eastern boundary.

Changes in the mei-yu front and LLJ are evident in various vertical cross sections. Figure 10 displays a meridional $(y-z)$ cross section of the equivalent potential temperature $\left(\theta_{e}\right)$ and wind $(v, w)$ fields averaged in the meridional belt $114^{\circ}-121^{\circ} \mathrm{E}$ from 12 to 15 June 1998 (left-hand panels). A zonal average from $114^{\circ}$ to $121^{\circ} \mathrm{E}$, roughly from the western boundary of the Jiangxi province to the east coast, was chosen because it contains the major part of simulated precipitation. The topography (also averaged from $114^{\circ}$ to $121^{\circ} \mathrm{E}$ ) is shown by the thick solid line at the bottom of each panel, with a peak of about $400 \mathrm{~m}$ around $26^{\circ}-28^{\circ} \mathrm{N}$. The mei-yu rain belt is evident by a maximum $\theta_{e}$ column (with high humidity), upward motion, and a low-level convergence zone around $28^{\circ}-30^{\circ} \mathrm{N}$. In the lower boundary layers, the dry, cold air is in the north, and the warm, moist air is in the south. Starting on 13 June, they converge to form a high humidity zone and rain belt in the YRV. In the corresponding figure for run W50 (not shown), the moisture convergence zone can still be identified. However, the convergence is much weaker and shallower, and the vertical motion is much smaller in W50 than in the CTRL. Thus, the large-scale background circulation dominates the development of the mei-yu front, while the moisture from the BOB fuels the moist condensation.

The contribution by BOB moisture to the mei-yu front and LLJ is manifested in the difference field between the CTRL and W50 runs, as shown in the right-hand panels of Fig. 10. The positive $\theta_{e}$ and $w$ differences are in the YRV. The latent heat released by condensation in the front induced secondary meridional circulations on both sides of it: an indirect one with a descending branch to the south and a direct one with a descending branch to the north. On the first two days (12 and 13 June), the $\theta_{e}$ difference is positive around $30^{\circ} \mathrm{N}$ and is concentrated between $25^{\circ}-30^{\circ} \mathrm{N}$ on 13 June, but later (except for 14 June), the descending dry air north of the front results in a negative $\theta_{e}$ difference, indicating a decrease of moisture to the north and hence an increase in the meridional moisture gradient. Also, the northerly wind difference is rather large north of the front, particularly at low levels, hindering the northward advance of moist air and consequently the northward movement of the rain belt. Therefore, the latent heating introduces a positive feedback through a direct secondary circulation north of the front. In the indirect secondary circulation south of the front, differences in the southerly flow in the lower layers, except for 15 June, are rather small. Based on Fig. 9a, the zonal averaging from $114^{\circ}$ to $121^{\circ} \mathrm{E}$ may underestimate the real magnitude of the $v$ difference. In a diagnostic study using observational data from a mei-yu case during the Taiwan Mesoscale Experiment (TAMEX), Chen et al. (1994) obtained similar results of relatively strong direct and weak indirect secondary circulations on the north and south sides of the mei-yu front, respectively. Because of the Coriolis effect, the southerly wind increases the westerly wind in the Northern Hemisphere to conserve momentum. However, because the increase in $v$ from moist processes is weak, the increase in westerly momentum from the Coriolis effect should also be weak. Therefore, in this case, the southwesterly LLJ is not due to the meridional secondary circulations.

Zonal-vertical $(x-z)$ cross sections of $\theta_{e}$ and $(u, w)$, and the differences between the CTRL and W50 runs, are shown in Fig. 11. Since the mei-yu rain belt is located around $28^{\circ}-29^{\circ} \mathrm{N}$ in the middle and lower reaches of the YRV and the LLJ is south of the rain belt during most of the simulation period, two $x-z$ cross sections are selected: one averaged over the zonal belt $28^{\circ}-29^{\circ} \mathrm{N}$ and the other $25^{\circ}-28^{\circ} \mathrm{N}$. The topography is highest over the Tibetan Plateau (at the west end of the panels), about 4000 and $2800 \mathrm{~m}$ at $100^{\circ} \mathrm{E}$ for the two zonal belts, respectively. The left-hand panels are $\theta_{e}$ and winds from the CTRL run, and the right-hand panels are the differences between the CTRL and W50 runs. From Fig. 11 , the whole layer from bottom to top is dominated by westerly winds, with a southerly component below about $400 \mathrm{hPa}$ and a northerly component in the upper layers, as seen from the $y-z$ cross sections in Fig. 10. The westerly flow is downslope following the topography on the eastern flank of the Tibetan Plateau then ascends farther east in association with condensational heating in the lower layers and upward motion ahead of the eastern Asian trough at upper layers. The differ- 
(a)

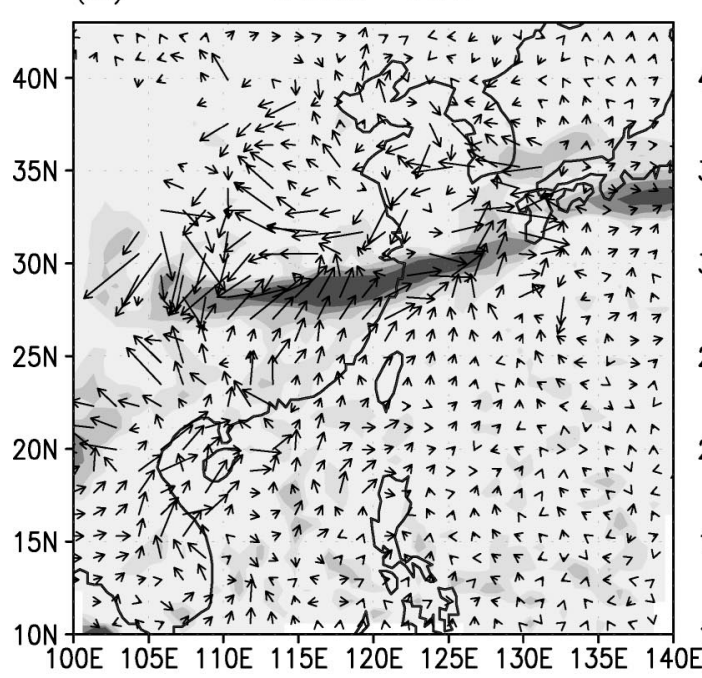

(c)

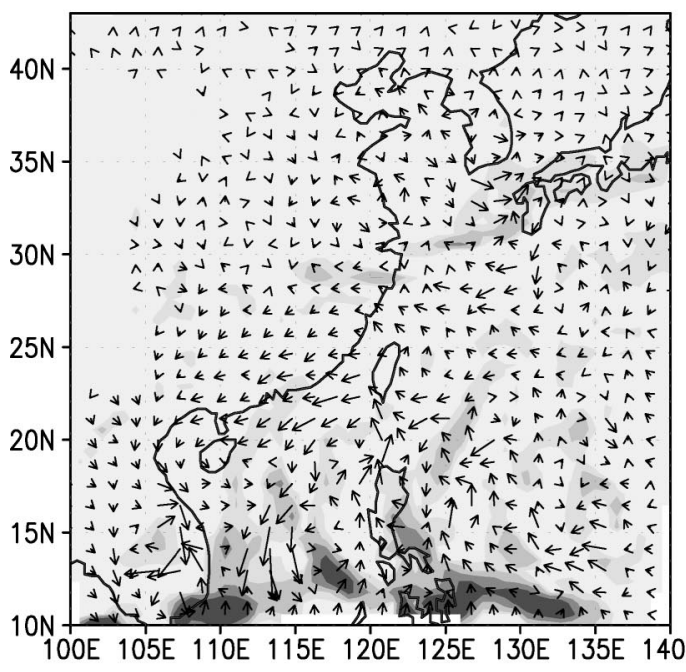

(b)

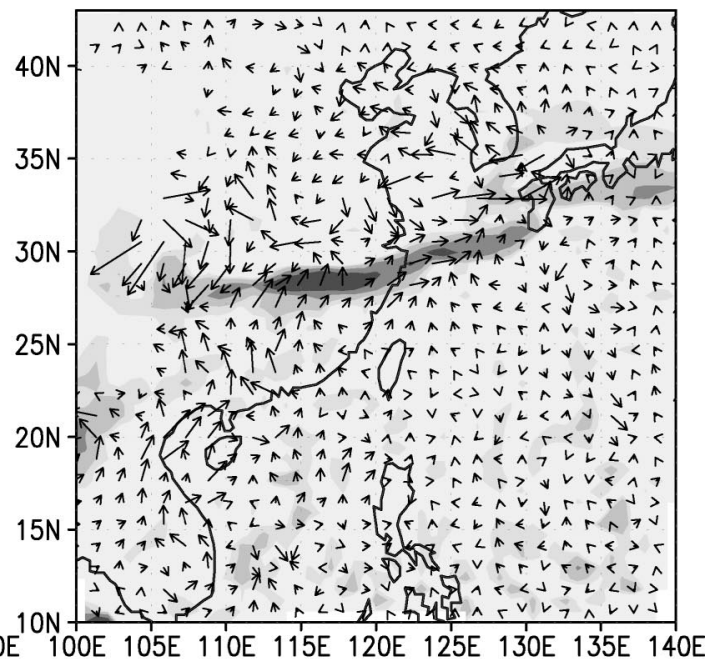

(d)

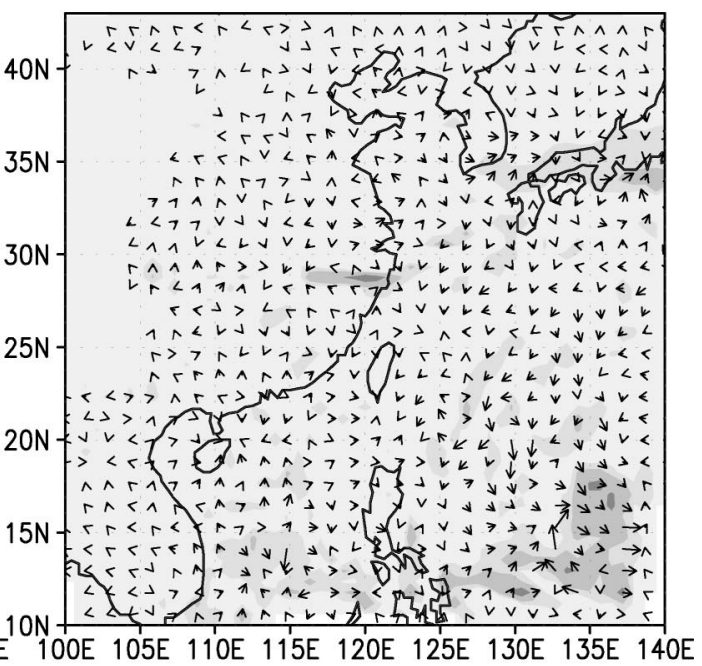

$\overrightarrow{5}$

$\mathrm{m} / \mathrm{sec}$

\section{$\begin{array}{lllll}1 & 5 & 15 & 30 & \mathrm{~mm} / \mathrm{d} \text { ay }\end{array}$}

FIG. 9. Differences in daily rain rate $\left(\mathrm{mm} \mathrm{day}^{-1}\right)$ and $850-\mathrm{hPa}$ wind $\left(\mathrm{m} \mathrm{s}^{-1}\right)$ between the control run and those with reduced moisture flux on one side of the outer boundary: (a) CTRL - W50, (b) CTRL - W80, (c) CTRL - S80, and (d) CTRL - E80, 13 Jun 1998

ence fields between the CTRL and W50 reveal the effects on the $\theta_{e}$ and wind velocity by moisture imported from the western boundary via the southwesterly LLJ. Accompanying the transport of warm, moist air from the west is upward motion due to condensational heating. The LLJ is also strengthened in the middle and lower reaches of the YRV around $115^{\circ}-125^{\circ} \mathrm{E}$ in the $25^{\circ}-28^{\circ} \mathrm{N}$ zonal belt by as much as $5 \mathrm{~m} \mathrm{~s}^{-1}$ (e.g., on 14 June). The westerly wind increase is especially strong at the eastern edge of the maximum in the $\theta_{e}$-difference field.

In the western part of the northern zonal belt $28^{\circ}-$ $29^{\circ} \mathrm{N}$, there is an easterly wind difference at 850 and $900 \mathrm{hPa}$ on 14 June. To the south, the corresponding wind difference in the western part of the $25^{\circ}-28^{\circ} \mathrm{N}$ belt is small. This means the low-level wind difference of CTRL - W50 in the horizontal is cyclonic and suggests that moisture from the BOB aids in cyclogenesis over 


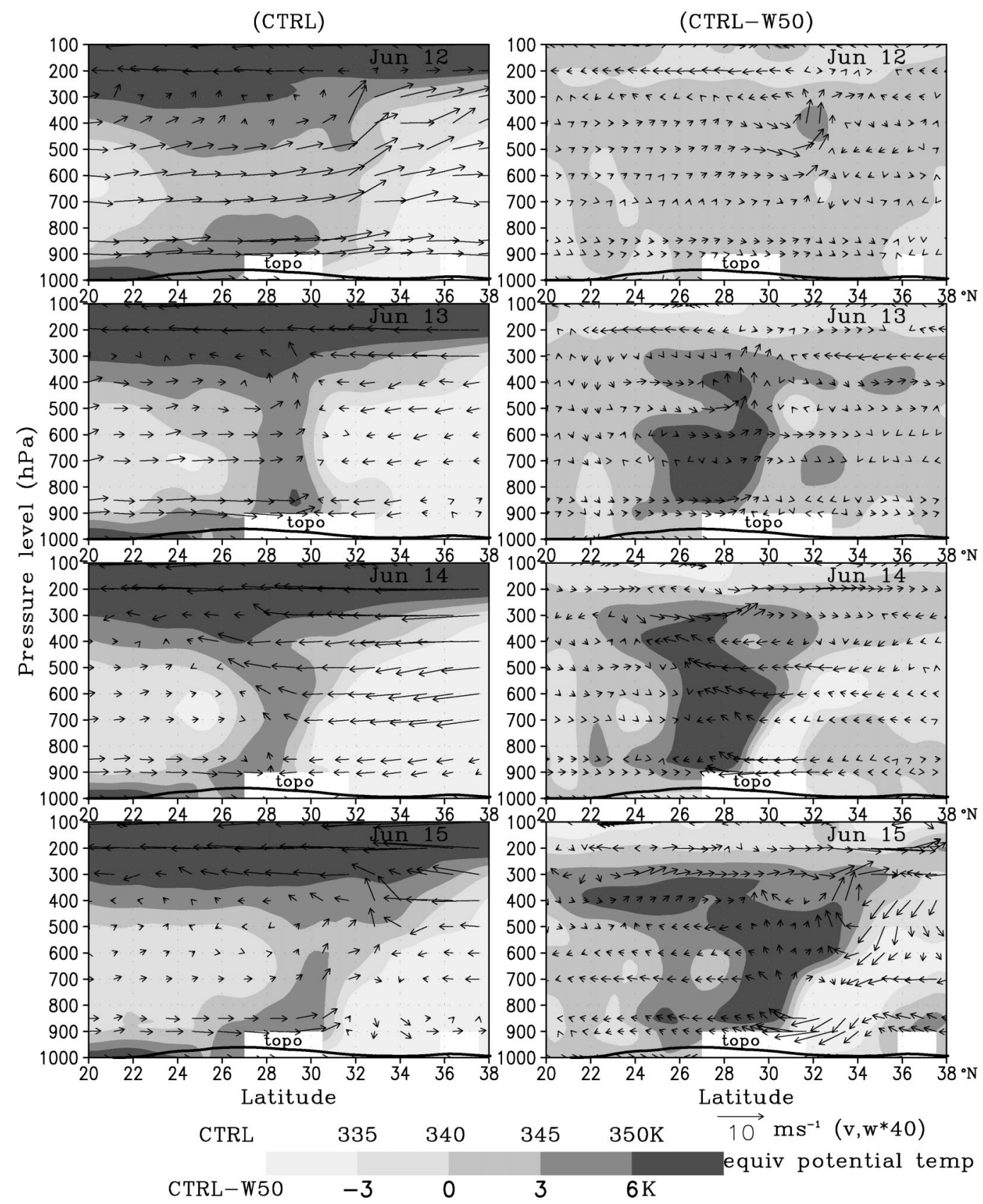

FIG. 10. Meridional-vertical $(y-z)$ cross section, averaged from $114^{\circ}$ to $121^{\circ} \mathrm{E}$, of (left) the CTRL equivalent potential temperature $\theta_{e}$ and $(v, w)$ wind and (right) their differences with W50, 12-15 Jun 1998. The thick line at the bottom is topography.

southwestern China [i.e., the development of a southwest mesoscale cyclone (Wu and Liu 1997)]. This subsequently affects the rainfall in the YRV as on 15 and 16 June when it propagates eastward following the LLJ. In the CTRL run, a mesoscale cyclone was indeed developing over $25^{\circ}-35^{\circ} \mathrm{N}, 105^{\circ}-110^{\circ} \mathrm{E}$ on 13 June (Fig. 5f). And, the precipitation difference (CTRL - W50) in Fig. 9a also showed a reduction in rainfall in the W50 run over the same area.
Examination of the vertical variation of the horizontal wind, in Fig. 10, shows that the southerly wind $(v)$ is strong in the lower troposphere (900-850 hPa) but weak in the middle troposphere $(700-400 \mathrm{hPa})$. In contrast, Fig. 11 shows that the westerly wind $(u)$ is strong not only in the lower troposphere but also in the middle troposphere. Hence, the northward atmospheric transport of moisture is confined in the lower troposphere, but the eastward transport of moisture occurs in the 


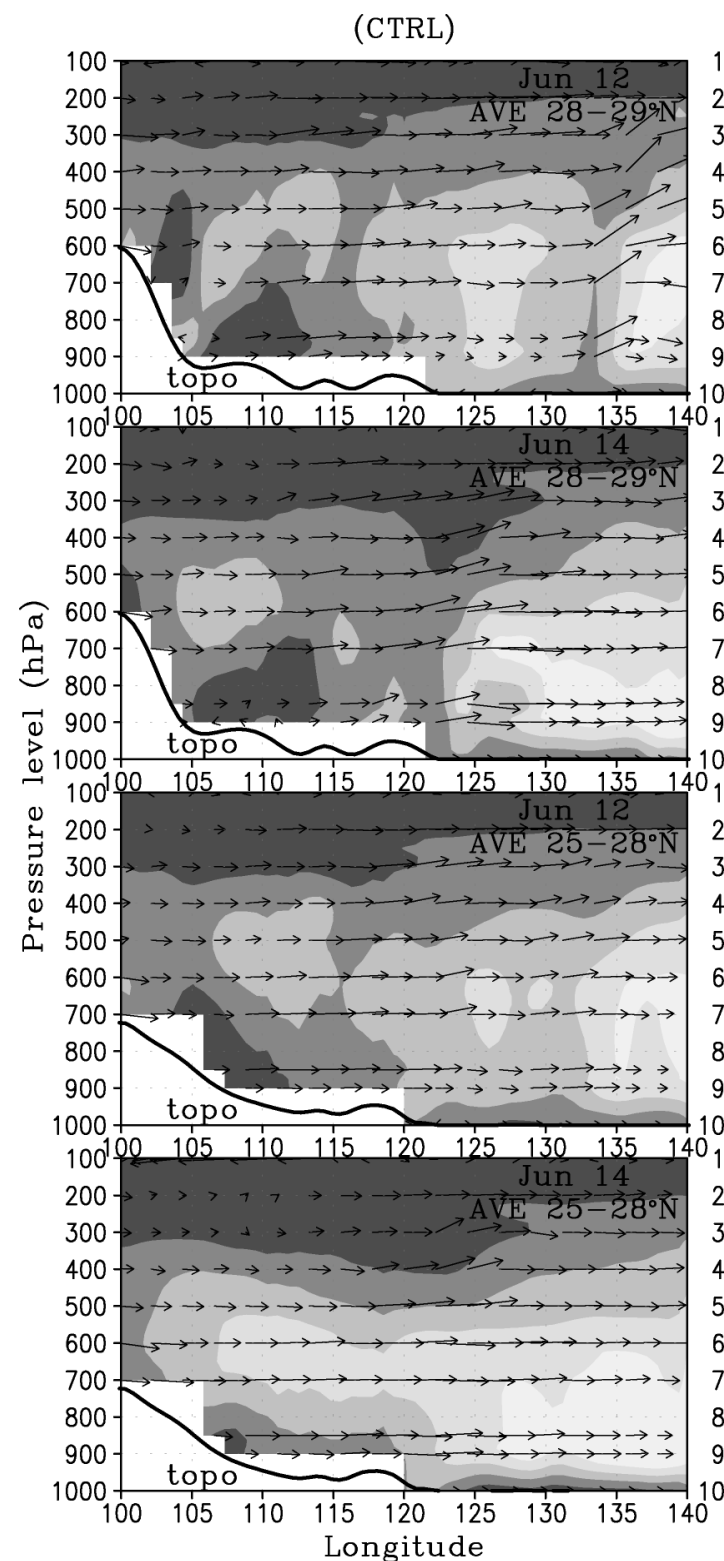

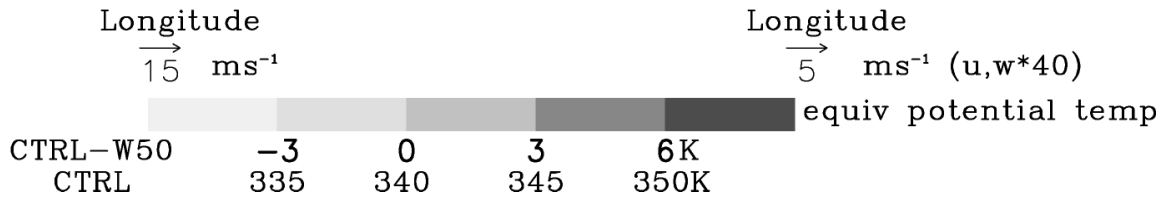

FIG. 11. Zonal-vertical $(y-z)$ cross section, averaged from $25^{\circ}$ to $28^{\circ} \mathrm{N}$ (lower four panels) and from $28^{\circ}$ to $29^{\circ} \mathrm{N}$ (upper four panels), of the (left) CTRL equivalent potential temperature $\theta_{e}$ and $(u, w)$ wind and (right) their differences with W50, 12 and 14 Jun 1998. The thick line at the bottom is topography. middle as well as lower troposphere. This is consistent with the diagnosed moisture fluxes of Ma and Bosart (1987) for a June 1983 mei-yu case, in which the moisture flux is northward in the lower troposphere but northeastward in the middle troposphere. In fact, midtropospheric transport is important in order for the moisture from the BOB to pass over the southeastern edge of the Yunnan-Guizhou Plateau and reach the YRV. The results of the W50(1.0-0.85), W50(0.85-0.7), and
W50(0.7-0.4) runs did show that both the moisture below and above the $\sigma=0.85$ level from the western boundary are significant for the rainfall in the YRV.

\section{d. Water budget analysis}

To quantify the moisture processes, the model's hydrology budget was calculated by horizontally and vertically integrating the continuity equation for atmo- 


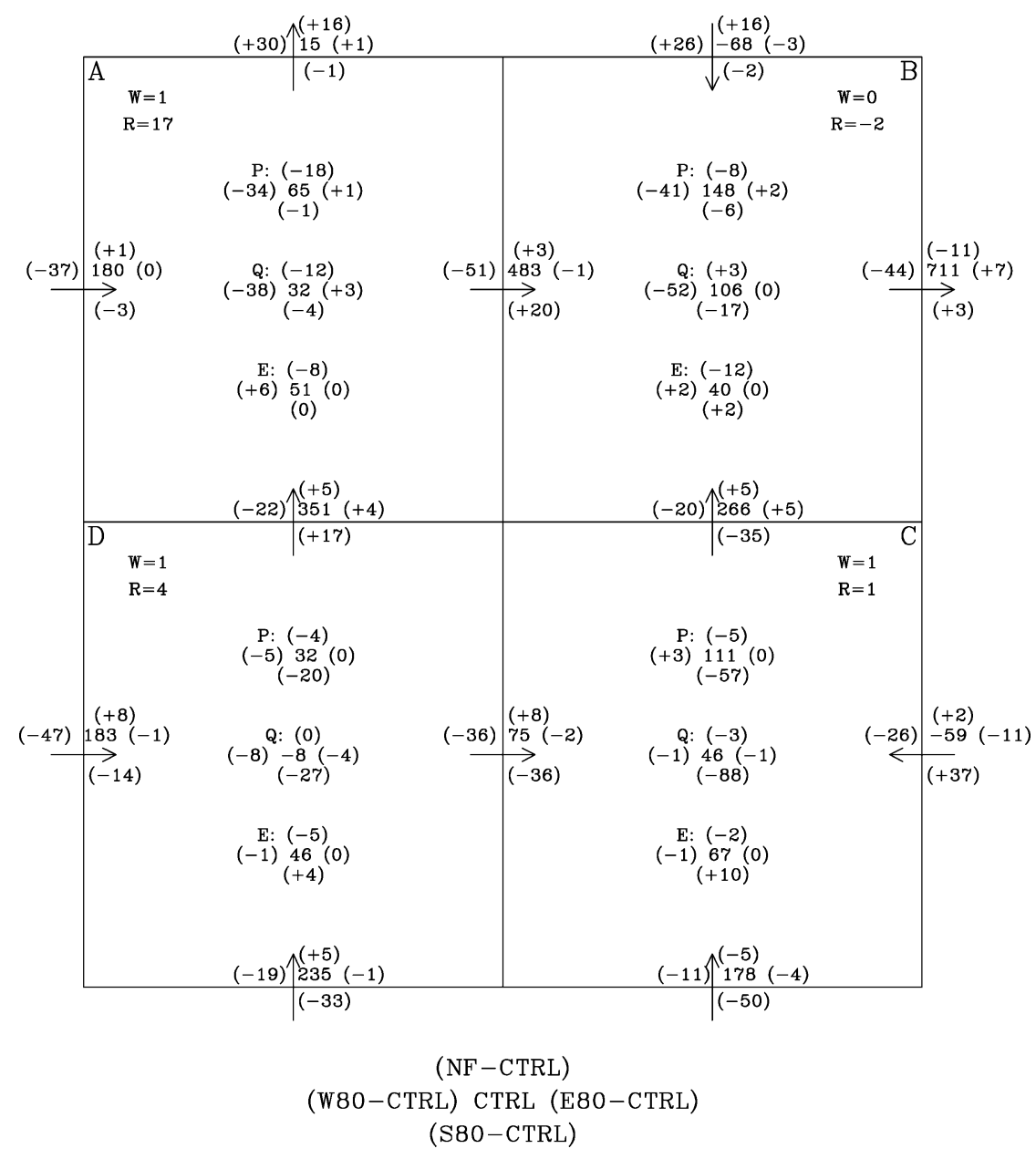

Fig. 12. Water budgets in domains A, B, C, and D (defined in Fig. 3), representing western China, the Yangtze River Valley and southern China, the South China Sea, and the Indochina peninsula, respectively. Here, $P$ is total precipitation, $E$ is total surface evaporation, $Q=F_{W}-$ $F_{E}+F_{S}-F_{N}$ is total moisture convergence, $W$ is total change in atmospheric water vapor, and $R$ is the residual of other terms. Units are in $10^{6} \mathrm{~kg} \mathrm{~s}^{-1}$.

spheric moisture around a rectangular domain (Bosilovich and Sun 1999), which yields

$$
W=F_{W}-F_{E}+F_{S}-F_{N}+E-P-R,
$$

where $W$ is the total change of atmospheric water vapor, which is generally a small term; $F_{W}, F_{E}, F_{S}$, and $F_{N}$ are the vertically integrated moisture fluxes across the western, eastern, southern, and northern boundaries of the budget calculation domain, respectively; $Q=F_{W}-F_{E}$ $+F_{S}-F_{N}$ is the total moisture convergence in the domain; $E$ is the total surface evaporation; $P$ is the total precipitation; and $R$ is obtained as the residual of other terms. In the calculation of $W$, the model-simulated surface pressure is used directly for simplicity without delineating the hydrostatic and nonhydrostatic differences. Considering that vertical integration is involved with the numerical control of the upper and lower boundary conditions, using (1) for budget calculations should not incur much error for the nonhydrostatic MM5. The re- sidual term $R$ collectively includes the errors in the other budget terms and also physically contains the change in liquid and solid water storage in the atmosphere. Numerically, the property of water vapor conservation in the second-order finite-difference scheme is disrupted by the additional mass divergence term in advection in the MM5's nonhydrostatic formulation [Dudhia 1993, Eq. (9)]. Moreover, the moisture flux terms in (1) are calculated by using the instantaneous 6-hourly model outputs; such a large time interval sometimes incurs large errors (Bosilovich and Sun 1999).

Water budgets are calculated over four rectangular domains A, B, C, and D (Fig. 12), roughly representing western China, the YRV and southern China, the SCS, and the IndoChina peninsula, respectively (see Fig. 3). To test the model sensitivity to the moisture sources, it is desirable to keep the atmospheric momemtum field as close to the CTRL as possible. Therefore, only the budget components of W80, S80, and E80 are used for 
comparison. The values in Fig. 12 are those averaged from 36 through $144 \mathrm{~h}$ in the model integration, allowing time for the initial and continuous moisture changes at the outer boundary of the domain to affect precipitation in the inner region of the domain over the YRV. The values in Fig. 12 are the total sum for each budget domain in units of $10^{6} \mathrm{~kg} \mathrm{~s}^{-1}$ of water. Only the relative changes are of interest. Budget components for the CTRL are shown in the middle, while the difference values for S80 - CTRL, W80 - CTRL, and E80 CTRL are below, on the left-hand side, and on righthand side of the CTRL value, respectively. The value above the CTRL one is for the no-feedback case for precipitation recycling, which will be discussed in section 5 . The values of $E, W$, and $R$ do not vary much among the different experiments; therefore, only the values from the CTRL are given in Fig. 12. The total atmospheric water vapor change $W$ is small.

For domain B, the CTRL total precipitation $P$ is 148 ; the surface evaporation $E$ is 40 ; the total moisture fluxes $F_{S}, F_{W}, F_{N}$, and $F_{E}$ are $266,483,-68$, and 711 , respectively; thus, the moisture convergence $Q$ is 106 . The B/C interface roughly divides continental China and the SCS, so the flux across this boundary, 266, represents the moisture source from the SCS. This flux from domain $\mathrm{C}$ is supported by surface evaporation over the SCS (67) and transport from the Tropics (178), the subtropical western Pacific (59) and the Indochina peninsula (75). Most of the moisture over domain B comes from its western boundary (from A to B), which in turn comes mostly from domain D via the southwesterly LLJ. In the W80 case, $F_{W}$ is reduced by 47 and 37 for domains $\mathrm{D}$ and $\mathrm{A}$, respectively, and $F_{W}$ for domain B is reduced by 51. Precipitation over domain $B$ is reduced substantially (by 41 or about $28 \%$ of $\mathrm{P}$ in the CTRL). Thus, the budget analysis also indicates that the mei-yu precipitation is sensitive to the BOB moisture source. In the $\mathrm{S} 80$ case, $F_{S}$ for domains $\mathrm{C}$ and $\mathrm{D}$ is reduced by 50 and 33 , respectively, and $F_{S}$ for domain $\mathrm{B}$ is reduced by 35 . However, the precipitation in domain $\mathrm{B}$ is only reduced by 6 . For domain $\mathrm{B}, F_{W}$ actually increases by 20 in the S80 case [i.e., positive $F_{W}(\mathrm{~S} 80-\mathrm{CTRL})$ ], indicating a slight strengthening of the LLJ in the S80, as seen from Fig. 9c. Thus, although the moisture transport from the Tropics is quite strong, its impact on the mei-yu precipitation in the YRV is small. The moisture that fuels the mei-yu precipitation is mostly from the southwest passing through domain D. The budget calculations also confirm that the moisture from the Pacific Ocean (E80 case) has little effect on mei-yu precipitation.

\section{Mesoscale effects-Local precipitation recycling}

An experiment was conducted in which the precipitation-surface evaporation interaction was turned off (i.e., no feedback, denoted by NF) in the land surface model PLACE. In the NF run, precipitation has no im- pact on the land surface processes; that is, the precipitation totally runs off immediately. The NF run is compared to the CTRL, in which the contribution from local precipitation to surface evaporation is retained. Since everything else between the runs is exactly the same, the difference between the CTRL and NF runs represents the effect of local precipitation recycling from the land surface. Precipitation differences and the energy and water vapor budgets are analyzed in the vicinity of the mei-yu front over the inner model domain (with grid size of $20 \mathrm{~km}$ ) during the period of maximum mei-yu precipitation. The 6-hourly rain rates (contours) and 850-hPa winds (vectors) are shown for 13 June in Figs. 13 and 14 for the CTRL and NF run, respectively. Figures $13 \mathrm{a}$ and $14 \mathrm{a}$ and Figs. $13 \mathrm{~b}$ and $14 \mathrm{~b}$ are for 0000 0600 and 0600-1200 UTC, respectively, corresponding to 0800-1400 and 1400-2000 LST. Figures 13c and 14c and Figs. 13d and 14d are for 1200-1800 and 18002400 UTC, respectively, corresponding to 2000 LST 13 June to 0200 LST 14 June and 0200-0800 LST 14 June. Cyclonic wind shear lies along about $29^{\circ} \mathrm{N}$, between weak northwesterlies to the north and strong southwesterlies to the south. The heavy precipitation belt is located south of the wind shear line. The north-south width of the mei-yu rain belt is about $2^{\circ}$ of latitude, or approximately $200 \mathrm{~km}$. Several precipitation maxima are found in the mei-yu rain belt. Maximum values can reach $50 \mathrm{~mm}(6 \mathrm{~h})^{-1}$, as shown in Figs. $13 \mathrm{c}$ and $13 \mathrm{~d}$. The strong nighttime precipitation on 13 June is not typical of other days in the simulation; therefore, it is not caused by the nocturnal strengthening of the LLJ upstream as proposed by Paegle et al. (1997) for the 1993 U.S. Midwest flood. Small differences in precipitation between the CTRL and NF can be observed on both the north and south sides of the major rain belt by comparing Figs. 13 and 14. The difference is smaller in the nighttime than in the daytime. This is reasonable because evaporation is stronger during the daytime.

The diurnal variation of evaporation is shown by the surface latent heat flux (LHFX) in the CTRL [i.e., LHFX(CTRL), contours] for the four quarters of a day in Fig. 15. Also shown is the evaporation due to precipitation recycling, as illustrated by the difference in LHFX between the CTRL and NF [i.e., LHFX(CTRL - NF), shades]. Over land, maximum LHFX and LHFX(CTRL - NF) occur in the daytime. In contrast, LHFX is larger at night over the ocean around (25$\left.28^{\circ} \mathrm{N}, 120-122.5^{\circ} \mathrm{E}\right)$. Since the magnitude of LHFX is much larger in the day than in the night over land, the daily averaged values are dominated by their daytime values. It is also clear that LHFX, as well as its diurnal variation, is very small along the mei-yu rain belt $\left(28^{\circ}-\right.$ $\left.30^{\circ} \mathrm{N}\right)$. This is reasonable because the atmosphere is almost saturated over the rain belt; hence, the evaporation should be small.

The major difference between the CTRL and NF runs, however, is the displacement of the heavy rainfall within the rain belt. The difference field between Figs. 13 and 


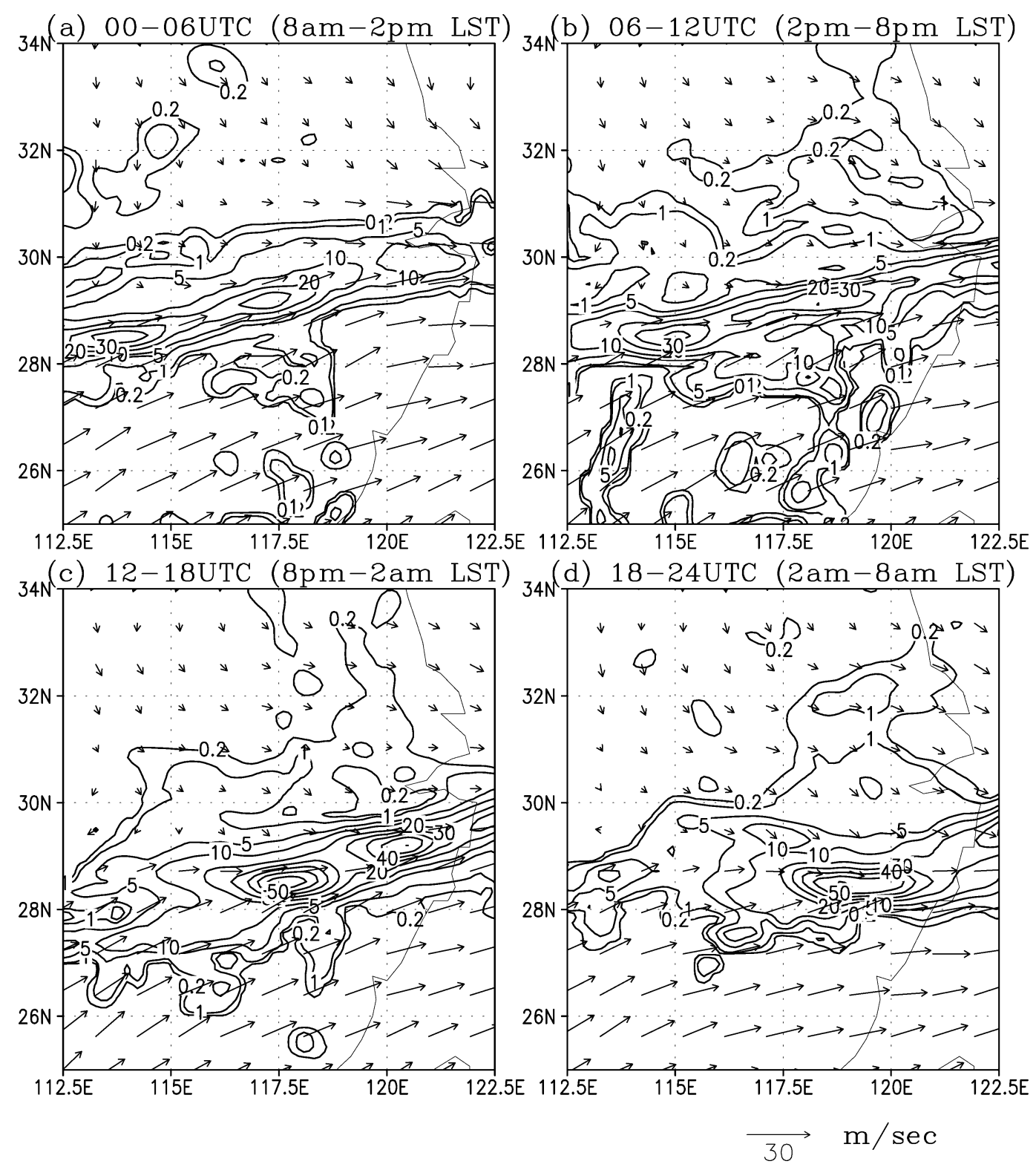

FIG. 13. CTRL 6-h rain rate and 850-hPa wind $\left(\mathrm{m} \mathrm{s}^{-1}\right)$ on 13 Jun 1998. The times (LST) in the brackets are those corresponding to the UTC ones. The contour levels are $0.2,1,5,10,20,30,40,50,60\left[\mathrm{~mm}(6 \mathrm{~h})^{-1}\right]$.

14 (not shown) indicates that precipitation recycling tends to increase precipitation on the southern half of the mei-yu rain belt but decrease it on the northern half from 0000 to 1800 UTC on 13 June, effectively shifting the belt about 50-100 km. But from 1800 to 2400 UTC on 13 June, the rain belt is shifted slightly to the northwest. The shift in the maximum rainfall location is also indicated in the daily rainfall totals, as shown in Fig. 16. The zone of heavy rainfall (larger than $20 \mathrm{~mm}$ day $^{-1}$ ) in the CTRL is marked by "rain belt." On 11 and 12 June, before the mei-yu onset, the precipitation in the CTRL and NF are very close to each other. Farther into the simulation, the differences between the CTRL and NF runs increase. In general, the precipitation in the CTRL is displaced to the south compared to that of the NF.

To understand why precipitation recycling relocates the heavy precipitation, surface heat fluxes and ground temperature between the CTRL and NF runs are compared. The meridional distribution of the daily mean LHFX and sensible heat flux (SHFX), zonally averaged from $114^{\circ}$ to $121^{\circ} \mathrm{E}$, is shown in Fig. 16. The LHFX is much larger than the SHFX in the CTRL. In the NF run, the soil dries up as precipitation is removed from the land surface processes. Therefore, the LHFX in the CTRL (thick solid line) is larger than that in the NF run (dash line), but vice versa for the SHFX. However, the opposing differences are not evenly compensated in the 


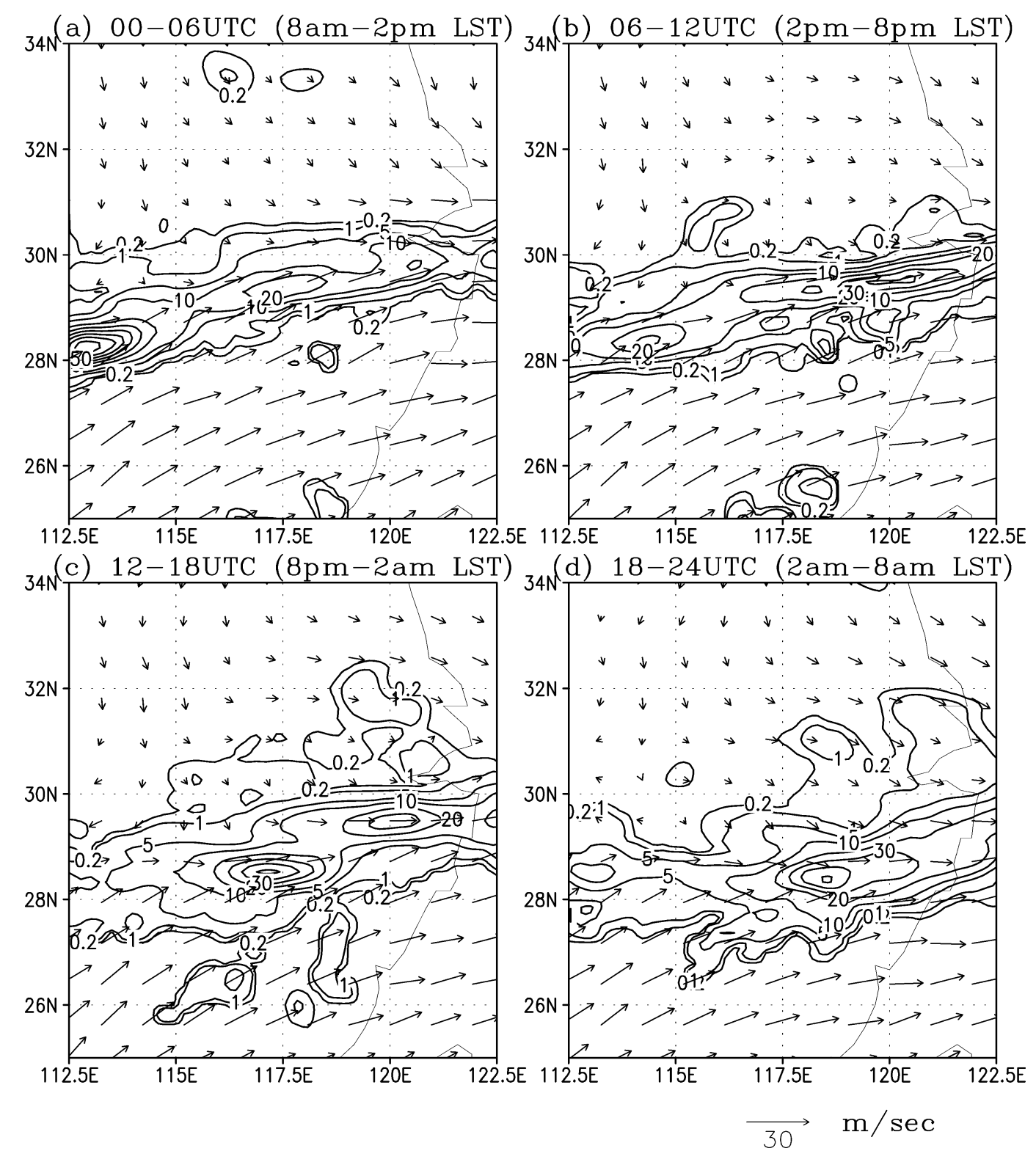

FIG. 14. Same as Fig. 13, except for NF, the run without precipitation-surface evaporation interaction.

total surface heat flux. Compared to the meridional distribution of precipitation, the LHFX difference is the smallest near the maximum precipitation center where the relative humidity is the highest and the atmosphere is almost saturated, thus hindering evaporation. The LHFX difference is larger on the two sides of the rain belt, particularly on the south side where the surface temperature is higher and the near-surface wind is stronger, thus promoting evaporation. Because of the cloud cover in the rain belt, longwave radiative cooling is reduced and SHFX is near zero at night. But south of the rain belt, strong winds in the LLJ allow sensible heat to be transferred from the atmosphere to the ground during nighttime. Therefore, the minimum of SHFX ap- pears to the south of the rain belt. The difference in SHFX between the CTRL and NF runs is also small over the mei-yu rain belt, but the magnitude of the difference is larger north of it, where stable precipitation (although it is light in the CTRL) and the associated clouds are removed by turning off precipitation recycling in the NF run (see the difference between Figs. 13 and 14).

Figure 17 shows the meridional distribution of the daily mean surface temperature $\left(T_{g}\right)$ averaged from $114^{\circ}$ to $121^{\circ} \mathrm{E}$. It is obvious that the surface temperature in the CTRL (solid line) is smaller than that in the NF run (dashed line) because of more precipitation-induced evaporation in the CTRL. Since evaporation is stronger 

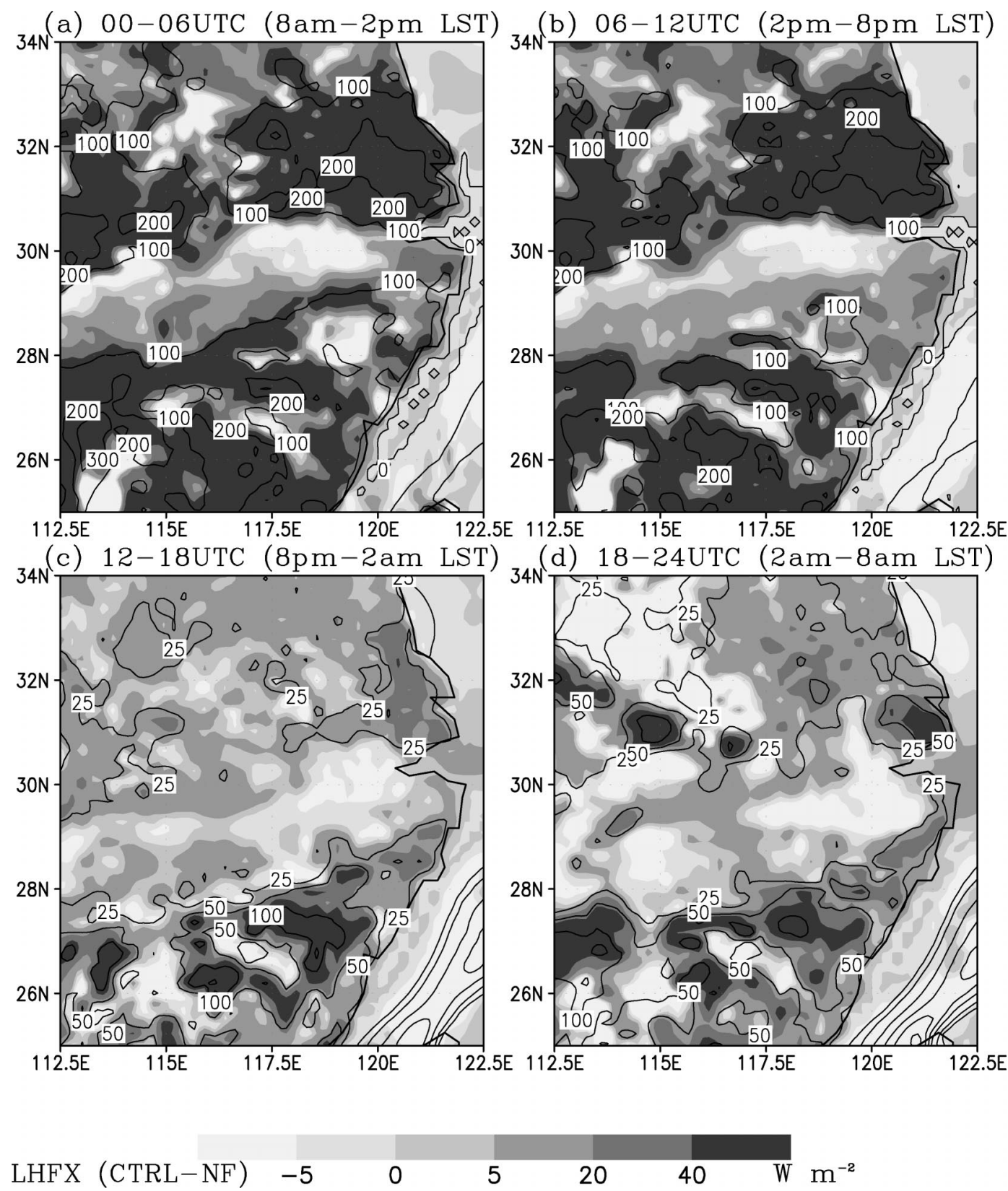

FIG. 15. Surface latent heat flux $\left(\mathrm{W} \mathrm{m}^{-2}\right)$ for the CTRL (contoured), and the difference between the CTRL and W50 (shaded), for 13 Jun 1998. The time in brackets is LST.

when the temperature is higher, the moisture and temperature changes are larger over warmer surfaces. The precipitation difference between the CTRL and NF runs is plotted in Fig. 17 [rain(CTRL - NF)]. The locations of the "rain belt" in Fig. 16 are also marked in Fig. 17. The rainfall difference between the CTRL and NF is almost zero at the beginning of the simulation (11 and 12 June) or when the precipitation is light (14 June). The difference becomes evident during the torrential rain. In general, such as on 13, 15, and 17 June, negative rain differences (CTRL - NF) occur over the region with cooler $T_{g}$, and positive rain differences (CTRL - NF) occur over warmer regions. This means heavy precipitation is shifted to the warmer side of the mei-yu rain belt, the south in this case. An exception seems to be 16 June in Fig. 17, but examination of Fig. 16 shows that the CTRL rainfall is still slightly shifted to the south compared to the NF run on this day. Physically more evaporation (Figs. 15 and 16) as well as the associated surface cooling by evaporation (Fig. 17) on the south side of the mei-yu rain belt in the CTRL run makes the moist atmosphere easier to saturate and hence produce more precipitation. 


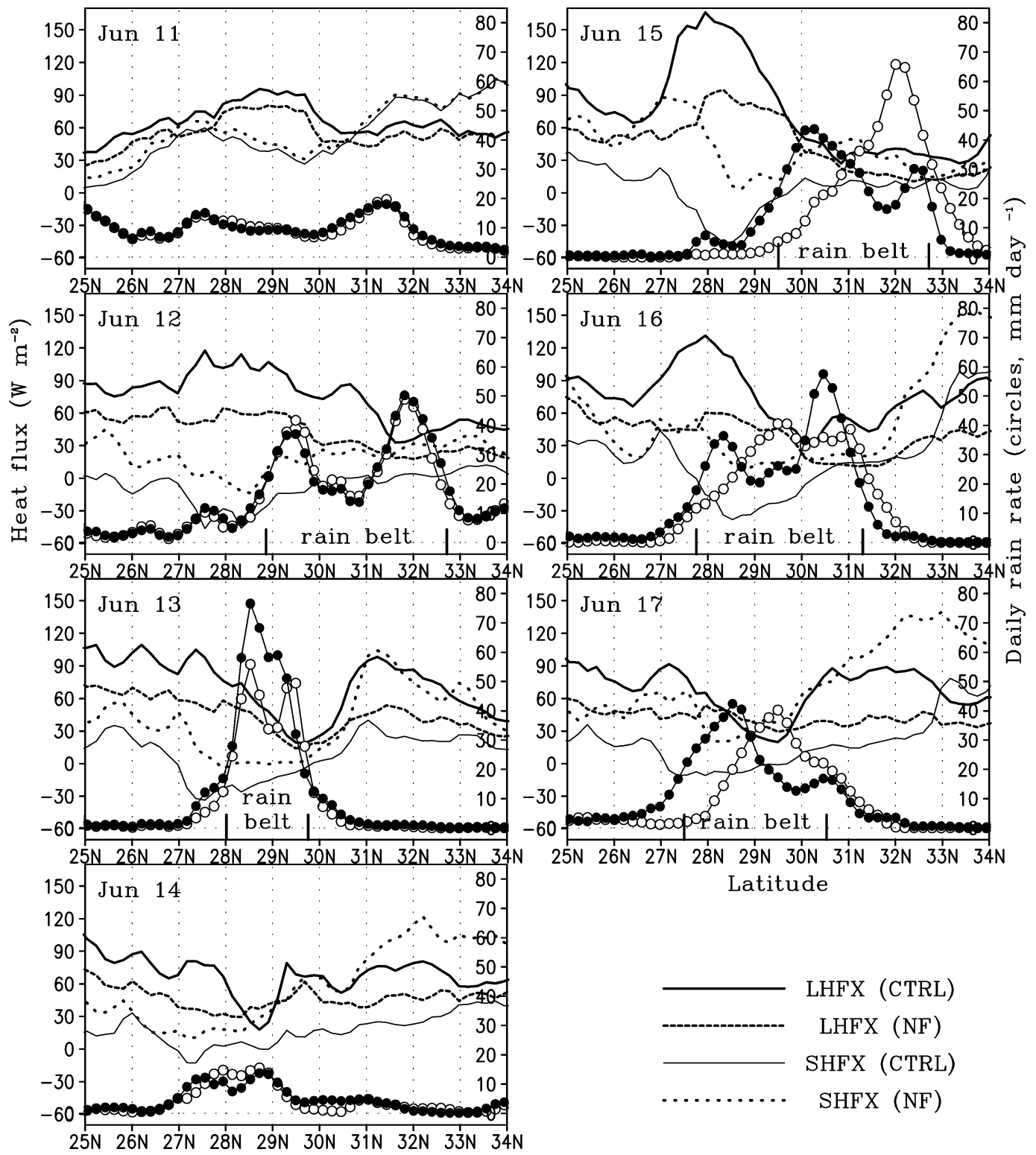

FIG. 16. Meridional distribution of the surface SHFX and LHFX ( $\mathrm{W} \mathrm{m}^{-2}$, left ordinate), averaged from $114^{\circ}$ to $121^{\circ}$ E: CTRL LHFX (thick solid), NF LHFX (dashed), CTRL SHFX (thin solid), and NF SHFX (dot), and daily rain rate (mm day ${ }^{-1}$, right ordinate) for CTRL and NF runs (solid and open circles, respectively), 11-17 Jun 1998.

Finally, the impact of precipitation recycling on total precipitation amount is examined. The differences in the water budgets between the NF and CTRL runs are given in Fig. 12. In domain B, covering the YRV and southern China where torrential mei-yu rainfall occurs, evaporation is reduced by 12 (or $30 \%$ ) when precipitation recycling is turned off. The precipitation in this domain is reduced by 8 (which is about $5 \%$ of the precipitation of the CTRL) in the NF run. In domain C, the SCS, surface evaporation over the ocean is hardly affected by the land surface scheme. In contrast, in the continental domain A (western China), although evaporation is only moderately reduced by 8 (or 16\%) in the
NF run, since torrential rain is not in this area, the local precipitation decrease is 18 (or 28\%), the most sensitive to the recycling. Over the Indochina peninsula and the adjacent ocean region (domain D), the sensitivity of precipitation to its recycling is moderate, with the precipitation being reduced by 4 (or 13\%) in the NF run.

\section{Summary and discussion}

By placing the outer model domain boundaries close to the moisture sources, with the southern boundary over the SCS and the western boundary facing the BOB, respectively, the impact of moisture transfer from those 

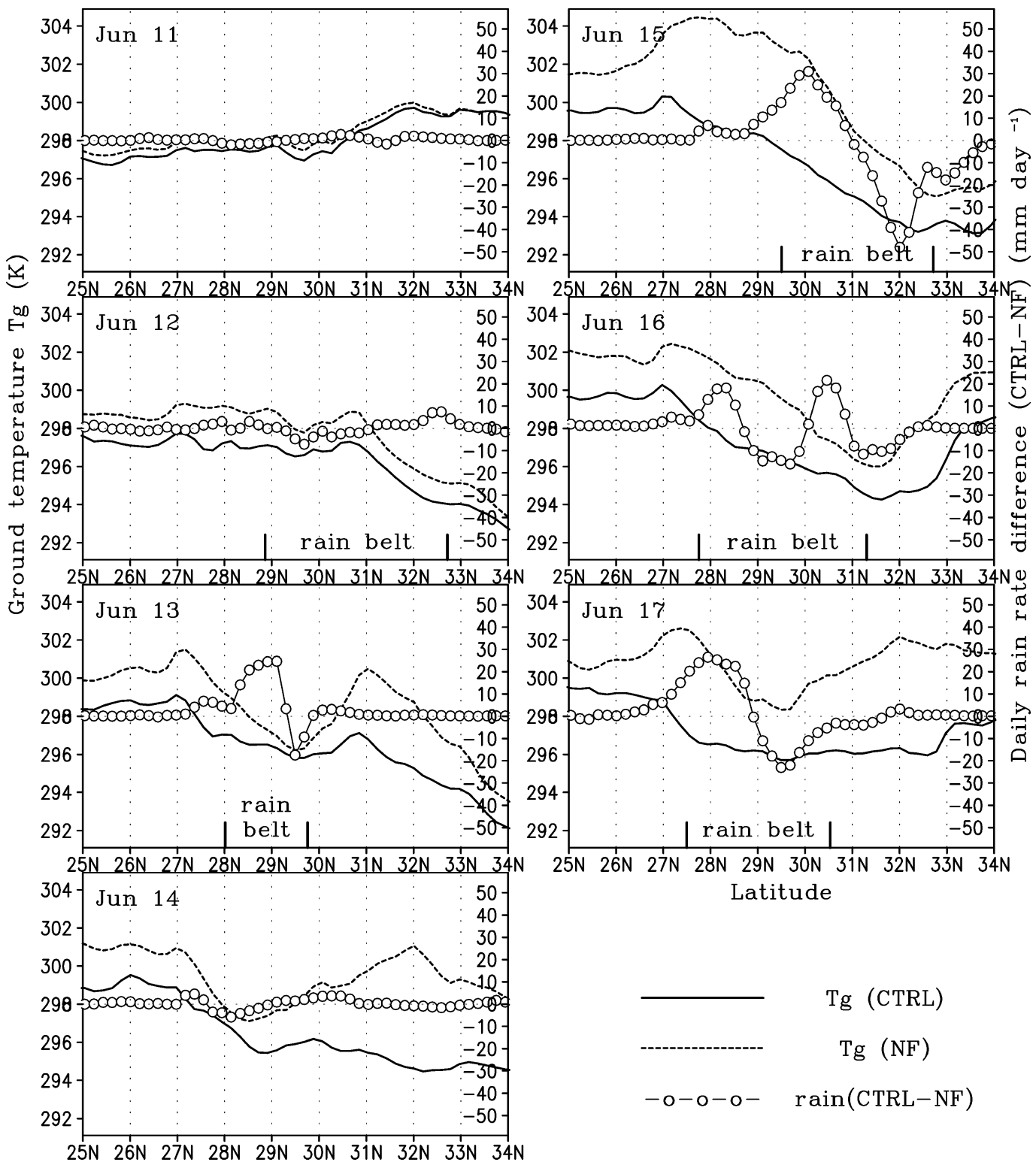

Latitude

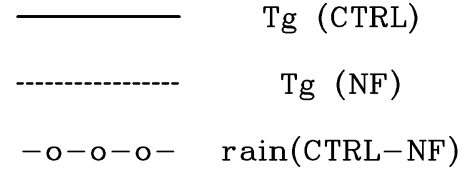

FIG. 17. Meridional distribution of ground temperature (K, left ordinate) for CTRL (solid) and NF (dashed), and the difference in daily rain rate between CTRL and NF (open circle, $\mathrm{mm} \mathrm{day}^{-1}$, right ordinate), averaged from $114^{\circ}$ to $121^{\circ} \mathrm{E}, 11-17$ Jun 1998.

sources can be delineated. The numerical results show that the moisture source most responsible for mei-yu precipitation over the YRV is the BOB, transported by southwesterly monsoonal flow passing over the southeastern edge of the Yunnan-Guizhou Plateau. In this case study, the mei-yu precipitation is not primarily due to the moisture from the SCS. These results agree with the synoptic analysis of Ma and Bosart (1987) for the mei-yu case of 23-25 June 1983 as well as the climate diagnostic study of Simmonds et al. (1999). For the 1991 summer flood case over the Yangtze-Huai River Valley, Wang et al. (2000) also found that the major source of moisture was from the $\mathrm{BOB}$ during most of the mei-yu period. These studies suggest that the precipitation efficiency for moisture from the BOB is higher than that from the SCS for mei-yu in the YRV. In addition, considering the important role of the LLJ in the moisture transport, the precision of its simulation is critical for the prediction of mei-yu precipitation.

Considering summer wind directions and the physical distances between the moisture source regions and the precipitation region, it seems reasonable to speculate that precipitation in southwest China and the YRV is more subject to moisture from the $\mathrm{BOB}$, but precipitation in southern China (particularly the Guangdong and Guangxi provinces) is due in greater part to moisture 
from the SCS. That is, for southern China, the precipitation efficiency of the moisture from the SCS could be higher than that from the BOB. It would be worthwhile to apply a similar modeling approach to that used in this study to early summer mei-yu precipitation cases over southern China.

The absence of torrential rain in the W50 case provides an opportunity to study the interaction among condensational heating from mei-yu precipitation, the LLJ, and the cyclonic wind shear along the mei-yu front by comparison to the CTRL simulation. In the W50 run, although the heavy precipitation is greatly reduced over the YRV, the 850-hPa southwesterly monsoonal flow over the vast area of southeastern China is still present, and its strength is similar to that in the CTRL run. This reveals the significance of the background large-scale circulation for mei-yu development, such as the interaction between the northwestward stretching of the subtropical high, the topographic blocking of the Tibetan Plateau, and the northwesterly flow from the north side of the Tibetan Plateau. However, in the vicinity of the mei-yu rain belt in the YRV, condensational heating from mei-yu precipitation changes the local mesoscale circulation that enhances low-level convergence and therefore strengthens the precipitation itself. Mei-yu latent heating adds an eastward wind component [in the wind difference field (CTRL - W50)] near the eastern edge of the mei-yu torrential rain and, therefore, strengthens the southwesterly LLJ. The low-level northward wind component in the indirect meridional secondary circulation south of the mei-yu rain belt acts to increase westerly momentum in the LLJ through the Coriolis effect. Therefore, the latent-heating-induced local mesoscale circulation also contributes to the formation of the LLJ in the southwesterly monsoonal flow, and the increased LLJ in turn enhances the mei-yu precipitation, forming a positive feedback. The latent-heating-induced direct meridional secondary circulation north of the mei-yu rain belt is stronger than the above indirect one, generating a strong northerly wind component at low levels behind the mei-yu rain belt. During the mei-yu period, the rain belt is usually quasi-stationary over the YRV for a prolonged time. The strong low-level northerly wind in the direct secondary circulation may be one of the factors hindering the northward advancement of the rain belt.

The numerical results indicate that one impact of precipitation recycling is to shift the location of the heavy precipitation area. In this case, there is no major precipitation along the path of the southwesterly LLJ before it reaches the YRV, hence saving plenty of moisture from the $\mathrm{BOB}$ for mei-yu precipitation. However, precipitation recycling modifies local thermodynamic structures by increasing atmospheric moisture content and at the same time decreasing ground temperature through surface evaporation of the precipitation. This effect is more pronounced over warmer areas. Therefore, precipitation recycling acts to shift the center of precipitation toward the warmer side of the mei-yu rain belt, usually to the south. This kind of shift could have some impact on hydrological applications such as flood management.

In this 1-week simulation, precipitation recycling acted to increase precipitation in local and adjacent regions. For long-term climate variation, the effect of precipitation recycling should be even more important. Although the precipitation recycling ratio (defined as the relative contribution of the recycled precipitation to the total precipitation) is smaller in Eurasia than that in North and South America and Africa, it can still reach about 0.1 in winter months and 0.2 in summer months (Brubaker et al. 1993). Besides the natural process of precipitation recycling, the human activity of irrigation also enhances surface evaporation. China has the largest irrigated area in the world, and much of this is in the form of flooded paddy fields, particularly in summer months in southern China (Simmonds et al. 1999). Therefore, further study on the problem of precipitation recycling in the context of a regional land-atmosphereclimate system is warranted.

Acknowledgments. We wish to thank P. Wetzel, X. Li, Y. Wang, Y. Jia, and W. Olson for discussion and S. Lang for editorial assistance. The study is supported by the NASA RELACS project. The constructive criticisms of two anonymous reviewers greatly improved this paper.

\section{REFERENCES}

Beljaars, A. C. M., P. Viterbo, M. J. Miller, and A. K. Betts, 1996: The anomalous rainfall over the United States during July 1993: Sensitivity to land surface parameterization and soil moisture anomalies. Mon. Wea. Rev., 124, 362-383.

Boone, A., and P. J. Wetzel, 1999: A simple scheme for modeling sub-grid soil texture variability for use in an atmospheric climate model. J. Meteor. Soc. Japan, 77, 317-333.

Bosilovich, M. G., and W.-Y. Sun, 1999: Numerical simulation of the 1993 midwestern flood: Land-atmosphere interactions. J. Climate, 12, 1490-1505.

Brubaker, K. L., D. Entekhabi, and P. S. Eagleson, 1993: Estimation of continental precipitation recycling. J. Climate, 6, 1077-1089.

Chen, C., W.-K. Tao, P.-L. Lin, G. S. Lai, S.-F. Tseng, and T.-C. C. Wang, 1998: The influence of the low-level jet during the development of mesoscale convective systems on a mei-yu front. Mon. Wea. Rev., 126, 349-371.

Chen, G. T. J., and C.-P. Chang, 1980: The structure and vorticity budget of an early summer monsoon trough (Mei-Yu) over southeastern China and Japan. Mon. Wea. Rev., 108, 942-953.

_ rainfall over northern Taiwan in the Mei-yu season. Mon. Wea. Rev., 116, 884-891.

Chen, S. X., S. F. Gao, and S. Yang, 1983a: The source of water vapor in the southern part of China in May and June and its abnormality (in Chinese). Proceedings of the Symposium on the Summer Monsoon in South East Asia, People's Press of Yunnan Province, 97-110.

,,$-- \ldots$, and Y. Q. Guo, 1983b: The transport and balance of water vapor in the area south of the Yangtze River in May and June (in Chinese). Proceedings of the Symposium on the 
Summer Monsoon in South East Asia, People's Press of Yunnan Province, 111-122.

Chen, X. A., and Y.-L. Chen, 1995: Development of low-level jets during TAMEX. Mon. Wea. Rev., 123, 1695-1719.

Chen, Y.-L., X. A. Chen, and Y.-X. Zhang, 1994: A diagnostic study of the low-level jet during TAMEX IOP 5. Mon. Wea. Rev., 122, 2257-2284.

Chengdu Central Observatory, 1982: A study of Sichuan extraordinarily heavy rainfall in July 1981 (in Chinese). Collected Papers of Sichuan Basin Heavy Rainfall in 1981, Sichuan Meteorological Bureau, 12-37.

Cho, H.-R., and G. T. J. Chen, 1995: Mei-yu frontogenesis. J. Atmos. Sci., 52, 2109-2120.

Ding, Y. H., 1994: Monsoon over China. Kluwer Academic, 419 pp. , and C. Y. Li, 1999: Onset and Activities of the South China Sea Monsoon and Its Interaction with the Ocean (in Chinese). Chinese Academic Press, 422 pp.

Dudhia, J., 1993: A nonhydrostatic version of the Penn State-NCAR mesoscale model: Validation tests and simulation of an Atlantic cyclone and cold front. Mon. Wea. Rev., 121, 1493-1513.

Eltahir, E. A. B., and R. L. Bras, 1996: Precipitation recycling. Rev. Geophys., 34, 367-378.

Grell, G. A., J. Dudhia, and D. R. Stauffer, 1994: A description of the fifth-generation Penn State/NCAR mesoscale model (MM5). NCAR/TN-398+STR, 117 pp. [Available from the National Center for Atmospheric Research, P. O. Box 3000, Boulder, CO 80307.]

Henderson-Sellers, A., Z.-L. Yang, and R. E. Dickinson, 1993: The project for intercomparison of land surface parameterization schemes. Bull. Amer. Meteor. Soc., 74, 1335-1349.

- J. Polcher, P. K. Love, K. McGuffie, and T. H. Chen, 1995: The Project for Intercomparison of Land Surface Parameterization Schemes (PILPS): Phases 2 and 3. Bull. Amer. Meteor. Soc., 76, 489-503.

Hsu, W.-R., and W.-Y. Sun, 1994: A numerical study of a low-level jet and its accompanying secondary circulation in a Mei-yu system. Mon. Wea. Rev., 122, 324-340.

Kasahara, A., and J.-H. Qian, 2000: Normal modes of a global nonhydrostatic atmospheric model. Mon. Wea. Rev., 128, 33573375 .

Kummerow, C., and Coauthors, 2001: The evolution of the Goddard profiling algorithm (GPROF) for rainfall estimation from passive microwave sensors. J. Appl. Meteor., 40, 1801-1820.

Kuo, Y.-H., L. Cheng, and R. Anthes, 1986: Mesoscale analyses of the Sichuan flood catastrophe, 11-15 July 1981. Mon. Wea. Rev., 114, 1984-2003.

Lau, K. M., and H. Weng, 2001: Coherent modes of global SST and summer rainfall over China: An assessment of the regional impacts of the 1997-98 El Niño. J. Climate, 14, 1294-1308.

_ , and H. T. Wu, 2001: Principal modes of rainfall-SST variability of the Asian summer monsoon: A reassessment of the monsoonENSO relationship. J. Climate, 14, 2880-2895.

- , and Coauthors, 2000: A report of the field operations and early results of the South China Sea Monsoon Experiment (SCSMEX). Bull. Amer. Meteor. Soc., 81, 1261-1270.

- , X. Li, and H. T. Wu, 2002: Evolution of the large scale circulation, cloud structure and regional water cycle associated with the South China Sea monsoon during May-June, 1998. J. Meteor. Soc. Japan, 80, 1129-1147.

Lynn, B. H., and Coauthors, 2001: Improved simulation of Florida summer convection using the PLACE land model and a 1.5- order turbulence parameterization coupled to the Penn StateNCAR mesoscale model. Mon. Wea. Rev., 129, 1441-1461.

Ma, K.-Y., and L. F. Bosart, 1987: A synoptic overview of a heavy rain event in Southern China. Wea. Forecasting, 2, 89-112.

Nagata, M., and Y. Ogura, 1991: A modeling case study of interaction between heavy precipitation and a low-level jet over Japan in the Baiu season. Mon. Wea. Rev., 119, 309-1336.

National Climate Center Report, 1998: Severe Flood and Anomalous Climate in China during 1998 (in Chinese). Meteorology Press, $139 \mathrm{pp}$.

Orlanski, I., 1975: A rational subdivision of scales for atmospheric processes. Bull. Amer. Meteor. Soc., 56, 527-530.

Paegle, J., K. C. Mo, and J. N. Paegle, 1996: Dependence of simulated precipitation on surface evaporation during the 1993 United States summer floods. Mon. Wea. Rev., 124, 345-361.

Qian, J.-H., and A. Kasahara, 2003: Nonhydrostatic atmospheric normal modes on beta-planes. Pure Appl. Geophys., 160, 13151358 .

Shen, J. Z., 1983: Atmospheric water vapor budget in summer monsoon over China (in Chinese). Proceedings of the Symposium on the Summer Monsoon in South East Asia, People's Press of Yunnan Province, 147-157.

Shin, X., M. Kimot, A. Sumi, A. Numagauti, and J. Matsumoto, 2001: Simulation of the 1998 East Asian summer monsoon by the CCSR/NIEW AGCM. J. Meteor. Soc. Japan, 79, 741-757.

Simmonds, I., D. Bi, and P. Hope, 1999: Atmospheric water vapor flux and its association with rainfall over China in summer. $J$. Climate, 12, 1353-1367.

Tao, S.-Y., and Y.-H. Ding, 1981: Observational evidence of the influence of the Qinghai-Xizang (Tibet) plateau on the occurrence of heavy rain and severe convective storms in China. Bull. Amer. Meteor. Soc., 62, 23-30.

_- , and L.-X. Chen, 1987: A review of recent research on the east Asian summer monsoon in China. Monsoon Meteorology, C. P. Chang and T. N. Krishnamurti, Eds., Oxford University Press, $60-92$.

Trenberth, K. E., 1999: Atmospheric moisture recycling: Role of advection and local evaporation. J. Climate, 12, 1368-1381.

Wang, H.-J., T. Matsuno, and Y. Kurihara, 2000: Ensemble hindcast experiments for the flood period over China in 1998 by use of the CCSR/NIES AGCM. J. Meteor. Soc. Japan, 78, 357-365.

Wang, W.-C., W. Gong, and H. Wei, 2000: A regional model simulation of the 1991 severe precipitation event over the YangtzeHuai River Valley. Part I: Precipitation and circulation statistics. J. Climate, 13, 74-92.

Wetzel, P. J., and A. Boone, 1995: A Parameterization for LandAtmosphere-Cloud Exchange (PLACE): Documentation and testing of a detailed process model of the partly cloudy boundary layer over heterogeneous land. J. Climate, 8, 1810-1837.

Wu, G.-X., and S.-J. Chen, 1985: The effect of mechanical forcing on the formation of a mesoscale vortex. Quart. J. Roy. Meteor. Soc., 111, 1049-1070.

_, and H. Z. Liu, 1997: Vertical vorticity development owing to down-sliding at slantwise isentropic surface. Dyn. Atmos. Oceans, 27, 715-743.

Zhang, S., S. Tao, Q. Zhang, and X. Zhang, 2001: Severe flooding in China during the summer of 1998 (in Chinese). Quart. J. Appl. Meteor., 12, 442-457.

Zhou, X.-P., and X.-F. Hu, 1984: A brief analysis and numerical simulation of the Sichuan extraordinarily heavy rainfall event. Proceedings First Sino-American Workshop on Mountain Meteorology, E. R. Reiter, B. Zhu, and Y. Qian, Eds., Science Press, $555-565$. 